\title{
South American Climatology and Impacts of El Niño in NCEP's CFSR Data
}

\author{
Timothy Paul Eichler and Ana C. Londoño \\ Department of Earth and Atmospheric Sciences, Saint Louis University, 3642 Lindell, Boulevard, O'Neil Hall 205, \\ St. Louis, MO 63108, USA
}

Correspondence should be addressed to Timothy Paul Eichler; teichler@slu.edu

Received 21 August 2013; Revised 2 October 2013; Accepted 17 October 2013

Academic Editor: Anthony R. Lupo

Copyright (c) 2013 T. P. Eichler and A. C. Londoño. This is an open access article distributed under the Creative Commons Attribution License, which permits unrestricted use, distribution, and reproduction in any medium, provided the original work is properly cited.

\begin{abstract}
Understanding regional climate variability is necessary in order to assess the impacts of climate change. Until recently, the best methods for evaluating regional climate variability were via observation networks and coarse-gridded reanalysis datasets. However, the recent development of high-resolution reanalysis datasets offers an opportunity to better evaluate the climatologically diverse continent of South America. This study compares NCEP's CFS reanalysis dataset with NCEP's coarser-resolution reanalysis II dataset to determine if CFS reanalysis improves our ability to represent the regional climate of South America. Our results show several regional differences between the CFSR and Re2 data, especially in areas of large topographical gradients. A comparison with the University of Delaware and TRMM precipitation datasets lends credence to some of these differences, such as heavier precipitation associated with anomalous $925 \mathrm{hPa}$ westerlies over northwestern Peru and Ecuador during El Niño. However, our results also stress that caution is advised when using reanalysis data to assess regional climate variability, especially in areas of large topographical gradient such as the Andes. Our results establish a baseline to better study climate change, especially given the release of IPCC AR5 model simulations.
\end{abstract}

\section{Introduction}

Representing summer climatology in South America is complicated by the diversity of its topographical features. As noted by Garreaud et al. [1], the Andes act as a climatological barrier separating arid conditions to the west in the PeruBolivian Atacama Desert from wet conditions to the east in the Amazon Basin. The aridity in the Atacama Desert is related to the position of the southeastern Pacific subtropical high, which causes large-scale subsidence $[2,3]$. The ability of the Andes to block tropospheric flow also results in a rain shadow in the Altiplano [4]. The precipitation that does occur in the area is confined mostly to austral summer (DJF) and is driven by diurnal convection and the westward transport of moisture from the interior of the continent [5-7].

With the recent implementation of high-resolution reanalysis datasets, it would be interesting to assess their ability to simulate South American climatology. This study compares the high-resolution CFSR data with coarse-grid reanalysis II (hereafter referred to as Re2) applied to South
American climatology and interannual variability. The highresolution reanalysis data will also allow us to detect features not seen in the coarse resolution data such as the climatological "Chaco low" $[1,2]$. We will demonstrate that the CFSR data is capable of capturing this and other features such as the effects of the Andes mountains on the general circulation in more detail than the Re2 data.

A key feature to South American climate is ENSO variability. The impacts of ENSO on South American climate have been well documented (e.g., [8-11]). On a regional basis, El Niño (La Niña) is associated with below (above) normal precipitation over tropical South America; above (below) normal precipitation over southeast South America and Central Chile; and warmer (colder) conditions over tropical and subtropical latitudes [1]. Over the western Altiplano, El Niño (La Niña) results in below (above) normal precipitation, with the western regions being more sensitive to ENSO variability due to moisture advection from the east [12]. However, in western Peru, there is a strong positive correlation with ENSO north of $11^{\circ} \mathrm{S}$, with a weaker ENSO relationship poleward of 
$11^{\circ} \mathrm{S}$ [13]. Wells [14] also stated the linkage between excessive rainfall in northern Peru and ENSO and used radiocarbon dating to determine that flooding events in the Holocene were due to El Niño. Further south, the Peru Current plays a major role in the aridity of the coastal zone between $15^{\circ} \mathrm{S}$ and $30^{\circ} \mathrm{S}$, as upwelling limits the moisture capacity of onshore winds resulting in an inversion accompanied by fog and drizzle [4]. As noted by Garreaud et al. [1], the limited spatial resolution of datasets such as NCEP's reanalysis data, ERA40 data, and the Global Historical Climate Network (GHCN) does not allow for accurate representations over coarse terrain. By analyzing the CFSR data, we will better resolve rainfall over complex terrain, as well as provide evidence of a poleward extension of the ENSO/precipitation relationship in western Peru.

We divide our paper into four main sections. Section 2 illustrates our data and methods. Section 3 details our comparisons between reanalysis and observed data products for DJF climatology. Section 4 assesses differences in the impacts of El Niño on various data products. Section 5 presents our conclusions.

\section{Data and Methods}

To assess South American climate and interannual variability, we focus on comparing two reanalysis datasets. The first dataset is the $\operatorname{Re} 2$ data which is presented on a $2.5^{\circ} \times 2.5^{\circ}$ (lat., lon.) horizontal grid $[15,16]$. The second is the CFSR data, on a $0.5^{\circ} \times 0.5^{\circ}$ (lat., lon.) grid derived from a T382 resolution version of NCEP's Climate Forecast System. The CFS is a fully coupled ocean/atmosphere model consisting of the Global Forecast System (GFS) atmospheric model at a T382 horizontal resolution with 64 vertical layers coupled to the MOM4 ocean model produced by the Geophysical Fluid Dynamics Lab (GFDL) (see [17] for more details). Since Austral summer is the main rainy season in tropical and subtropical areas, we focus our attention on diagnostics for DJF in these regions. To ensure an accurate comparison, we analyzed the CFSR and Re2 data for all DJFs from 1979-1980 to 2008-2009. To verify the reanalysis data, we compare reanalysis precipitation data to the University of Delaware precipitation dataset from 1950 to 2010 provided by the NOAA/OAR/ESRL PSD, Boulder, CO, USA, from their website at http://www.esrl.noaa.gov/psd/. The University of Delaware (UD) precipitation data, which was originally developed by Legates and Willmott [18], is a land-based product with a horizontal resolution of $0.5^{\circ} \times 0.5^{\circ}$ (lat./lon.). This dataset provides an excellent comparison, since it has the same spatial resolution as the CFSR. To ensure a direct comparison to the reanalysis products, we generate DJF precipitation from UD from 1979-1980 to 2008-2009. To provide a final comparison, we also include a DJF rainfall rate climatology from Tropical Rainfall Measuring Mission (TRMM) level 3 data from 1998-1999 to 2012-2013. The TRMM level 3 rainfall dataset merges Ground-Based Climate Rainfall products (GPCC) with TRMM satellite rainfall data. The final product is a gridded rainfall dataset with a horizontal resolution of $2.5^{\circ} \times 2.5^{\circ}$ (lat./lon.). For more information
TABLE 1: El Niño composites (DJF).

\begin{tabular}{|c|c|}
\hline Strong $\mathrm{H}$ & $\begin{array}{c}1982 / 83,1986 / 87,1991 / 92,1994 / 95,1997 / 98 \\
\text { and } 2002 / 2003\end{array}$ \\
\hline Str & $\begin{array}{c}1984 / 85,1988 / 89,1998 / 99,1999 / 2000 \text {, and } \\
2007 / 2008\end{array}$ \\
\hline
\end{tabular}

on GPCC data, see $[19,20]$. More information on the TRMM rainfall algorithm can be found at $[19,21,22]$. Since the TRMM data is taken over a different time period, we generate the rainfall plot from the TRMM Online Visualization and Analysis System (Tovas: http://gdatal.sci.gsfc.nasa.gov/daacbin/G3/gui.cgi?instance_id=TRMM_Monthly) for qualitative analysis only.

For our results, we focus on differences in climatologies and interannual variability related to El Niño. In our assessment of climatology, we examine South American climate by choosing several diagnostics from the reanalysis datasets including precipitation, winds $(925 \mathrm{hPa}, 200 \mathrm{hPa})$, and geopotential height ( $925 \mathrm{hPa}, 200 \mathrm{hPa})$. We also compute the $925 \mathrm{hPa}$ divergence field to examine the relationship between the low-level circulation and precipitation, which is especially useful in areas of complex topography such as in western Peru. Generating these climatologies serves three purposes; first, they provide a good baseline to how similar the various products are before we assess an ENSO response. Second, utilizing these diagnostics gives a good description of the climatological low-level and upper-level circulation for South America. Finally, assessing $925 \mathrm{hPa}$ climatology with different spatial resolution allows us to evaluate differences related to topographical gradient as well as error due to model interpolation below the level of the Andes.

To explore the impacts of the strongest ENSO events on South American climate, we deploy a compositing technique to assess the effects of strong El Niño/La Niña episodes. We define warm (El Niño) and cold (La Niña) events based on the ENSO intensity scale (EIS) developed by Kousky and Higgins [23]. The EIS is a five-class intensity scale that is calculated by doubling the oceanic Niño index (ONI), defined as the 3-month running mean of sea surface temperature (SST) anomalies for the Niño 3.4 region, which extends from $120^{\circ} \mathrm{W}-170^{\circ} \mathrm{W}$ and $5^{\circ} \mathrm{S}-5^{\circ} \mathrm{N}$. The five categories are (1) strong El Niño, (2) weak/moderate El Niño, (3) neutral conditions, (4) weak/moderate La Niña, and (5) strong La Niña. By utilizing the EIS classification system, we more objectively composite the strongest El Niño and the strongest La Niña events. Table 1 shows the EIS value and events chosen to represent the strongest El Niño and the strongest La Niña periods. To assess statistical significance of our composites, we normalize by dividing the composite by the standard deviation taken over all DJFs. We then difference the normalized composites to assess the impact of the strongest El Niño/La Niña events.

Since composites only give an assessment of differences between the extreme phases of El Niño/La Niña, we also compute the linear correlation between the EIS index and the diagnostics described above to assess their overall relationship to ENSO. Since regional climate assessments are often 


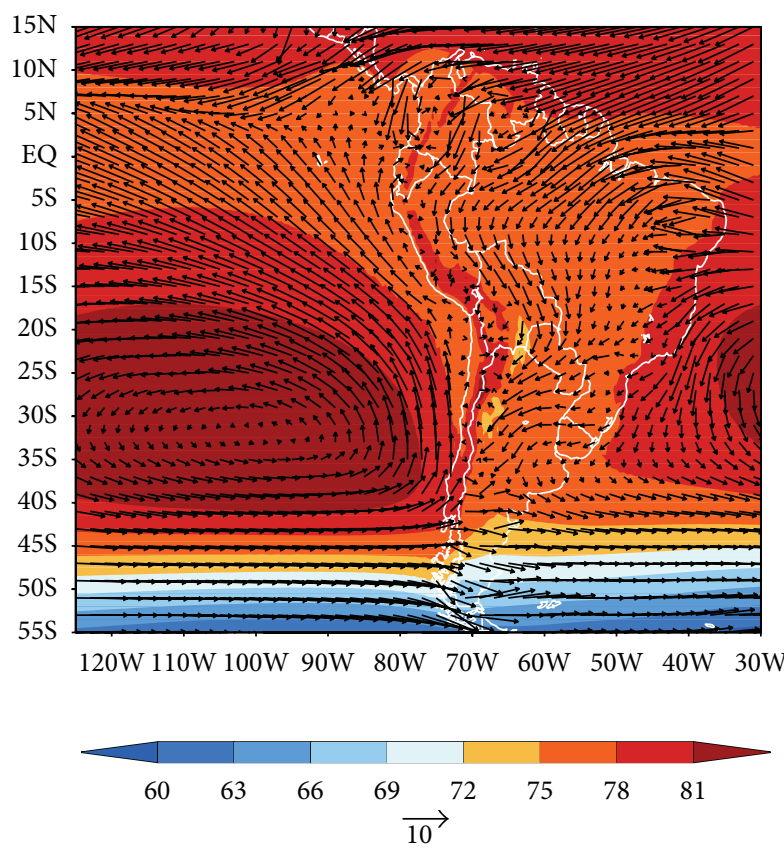

(a)

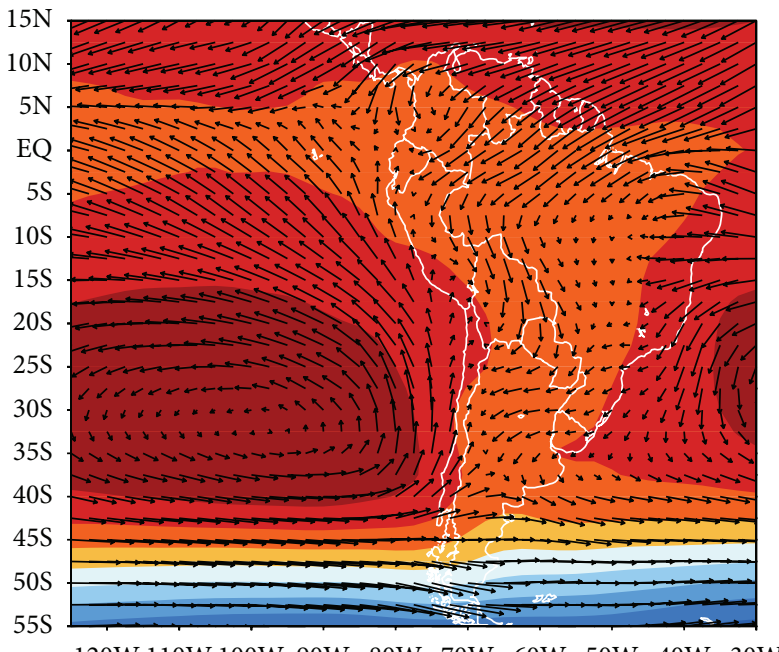

120W 110W 100W 90W 80W 70W 60W 50W 40W 30W

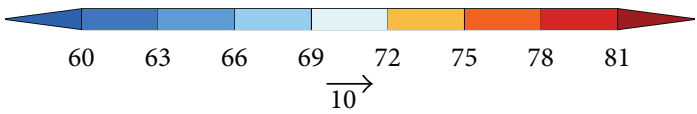

(b)

Figure 1: (a) CFSR DJF mean $925 \mathrm{hPa}$ height shaded (dm), $925 \mathrm{hPa}$ wind vector (m/s) from 1979/1980 to 2008/2009 and (b) like (a), except for Re2.

done with respect to ENSO, examining the composites in concert with the correlations will provide a guide to how sensitive regional climate assessment is as a function of which dataset is used. To assess significance, we apply a 2-tailed test at the $95 \%$ significance level.

\section{Results: South American Climatology}

The austral summer mean $925 \mathrm{hPa}$ heights and winds are shown in Figure 1 for CFS reanalysis (CFSR) and reanalysis II $(\operatorname{Re} 2)$ data, respectively. The SE subtropical Pacific ridge is prominent in both datasets, centered near $34^{\circ} \mathrm{S}$ and $100^{\circ} \mathrm{W}$. A reflection of the Andes is seen in the CFSR data via a narrow area of higher heights over western South America from $40^{\circ} \mathrm{S}$ to $5^{\circ} \mathrm{N}$. An area of lower heights in the CFSR data in northwestern Argentina, combined with a cyclonic turning of the $925 \mathrm{hPa}$ wind reflects the position of the Chaco low (Figure 1(a)). In contrast, the Re2 data lacks this feature, although some indication of a cyclonic turning of the $925 \mathrm{hPa}$ wind is evident (Figure 1(b)). The improved representation of the Chaco low in the CFSR data relative to Re2 is likely due to the CFSR's better representation of the Andes mountains; this is suggested by Vera et al. [24], who indicated that the barrier effect of the Andes intensifies the Chaco low.

For precipitation, both the CFSR and Re2 data depict several climatological features, such as the Intertropical Convergence Zone (ITCZ) and enhanced precipitation resulting from upsloping of northerly winds from the Amazon (Figure 2). However, several differences are also seen. For example, the precipitation over the Andes shows greater detail when compared to the $\operatorname{Re} 2$ data likely due to topographical features better captured by the CFSR data (cf. Figure 2(a) with Figure 2(b)). An area of more intense precipitation is also seen in north-central Brazil in CFSR, once again likely due to the influence of local topography interacting with $925 \mathrm{hPa}$ northeasterlies from the Atlantic (Figure 2(a)). A similar response is found on the southern tip of Chile, where increased precipitation in the CFSR data is linked to upsloping from $925 \mathrm{hPa}$ westerlies (Figure 2(a)). Another interesting feature is seen in the Amazon basin, where CFSR data has a precipitation maximum in a region bounded by $5^{\circ} \mathrm{S}-10^{\circ} \mathrm{S}, 60^{\circ} \mathrm{W}-50^{\circ} \mathrm{W}$. A careful inspection of Figure 2 shows that $925 \mathrm{hPa}$ wind convergence in $\mathrm{Re} 2$ is also displaced eastward relative to CFSR (cf. Figures 2(a) and 2(b)).

To determine if the differences between the CFSR and Re2 rainfall are related to spatial resolution, we compare the Re2 and CFSR rainfall over South America to UD and TRMM data (Figure 3). From Figure 3, it is clear that the UD rainfall maximum in the Amazon agrees with the CFSR data, as opposed to the Re2 data (Figure 3), supporting the westward displacement of the $925 \mathrm{hPa}$ low-level convergence shown in CFSR. UD shows a weaker precipitation maximum in southern Chile than either CFSR or Re2 (Figure 3). To provide further perspective, we include a plot of rainfall rate from TRMM data shown in Figure 3(d). The enhanced rainfall rate over the Amazon supports the UD and CFSR results. An area of higher rainfall rate is also noted in TRMM over western Chile suggesting a topographical influence associated with low-level westerlies (Figure 3(d)). However, the CFSR in this region produces much greater rainfall than the UD data in this region (cf. Figure 3(a) with Figure 3(c)). As we will show below, the greater rainfall in the CFSR data may be due to local circulation created by model topography. 


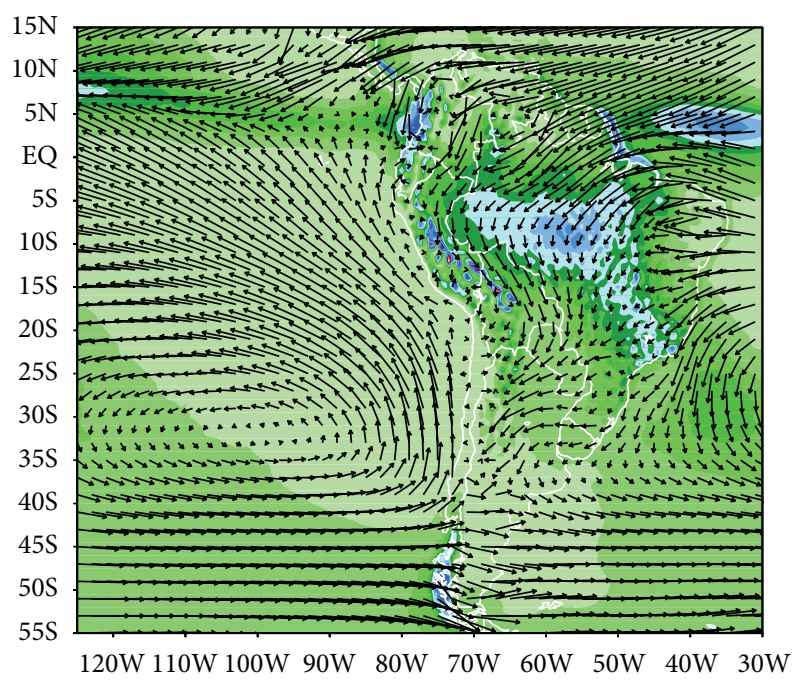

$\begin{array}{llllllllllllllllll}2 & 4 & 6 & 8 & 10 & 12 & 14 & 16 & 18 & 20 & 22 & 24 & 26 & 28 & 30 & 32 & 34 & 36\end{array}$ $\overrightarrow{10}$

(a)
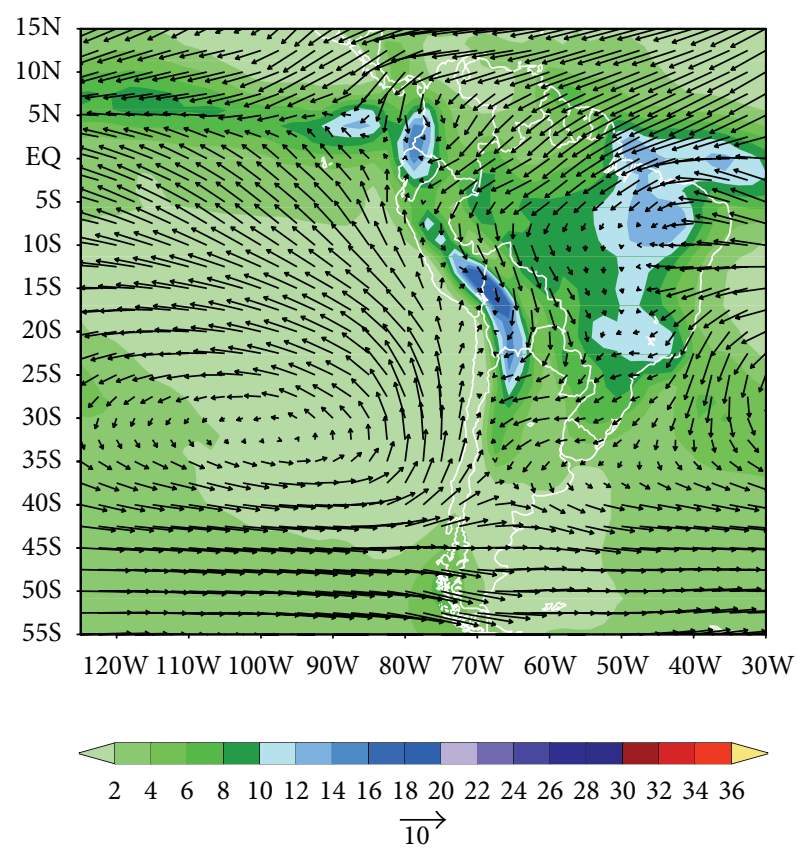

(b)

Figure 2: (a) CFSR DJF mean precipitation (mm/day), $925 \mathrm{hPa}$ wind vector (m/s) from 1979/1980 to 2008/2009, (b) like (a), except for Re2.

Since Peru has a sharp topographical gradient, Figure 4 shows precipitation for this region. To illustrate the complexity of the local circulation, we include the $925 \mathrm{hPa}$ divergence field for CFSR and Re2. Overall, the rainfall pattern for UD more closely resembles the CFSR precipitation rather than the Re2 (cf. Figure 4(c) with Figure 4(a)). The Re2 rainfall shows a broad maximum over the Andes associated with a single band of $925 \mathrm{hPa}$ convergence (Figure 4(b)). In contrast UD precipitation shows several areas of localized maxima over Peru, as opposed to the broad maxima seen in Re2 (cf. Figures 4(c) and 4(b)). However, CFSR's precipitation shows an even more complex pattern, with 2 bands of maxima across Peru from the western Cordillera Oriental and the more eastern Cordillera (Figure 4(a)). Consistent with the CFSR precipitation, the $925 \mathrm{hPa}$ divergence pattern is more complex, with a band of $925 \mathrm{hPa}$ convergence just inland from the coast (Figure 4(a)). Despite the greater detail shown for CFSR, UD data does not confirm the double-maxima structure over Peru. However, topographically-induced precipitation is noted north of Lake Titicaca, likely associated with the rugged topography of the Cordillera Real (Figure 4(c)). An examination of TRMM rainfall data (Figure 4(d)) also supports the maximum over the Cordillera Real. Despite the CFSR's ability to show more detailed topographically induced areas of rainfall than Re2, the inability of UD to confirm these features casts doubt on this result. It is quite feasible that precipitation in this region is artificially induced by the model's representation of the low-level wind field below the level of topography related to the Andes. This is also suggested by Silva et al. [25], who found that the intensity of the CFSR and Re2 rainfall over the Andes is likely due to a wet bias rather than an improved capability to display localized regions of intense rainfall. However, Silva et al. [25] also suggest that the CFSR precipitation is more realistic than Re2 due to its finer spatial scale.

Finally, the $200 \mathrm{hPa}$ circulation in CFSR and Re2 are in fairly good agreement, which is not surprising given that this is above any topographical feature (Figure 5). Both datasets feature the Bolivian High centered at approximately $17^{\circ} \mathrm{S}, 65^{\circ} \mathrm{W}$, with primarily zonal flow at mid-to high latitudes (Figure 5). A minor difference is that the Re2 data did produce a greater area of $>124 \mathrm{dm}$ and heights in the tropics, along with slightly lower heights in extreme southern South America relative to CFSR data (cf. Figure 5(a) with Figure 5(b)).

\section{ENSO Impacts}

To investigate the impacts of El Niño on low-level circulation, Figure 6 shows $925 \mathrm{hPa}$ height and $925 \mathrm{hPa}$ wind composite for El Niño relative to La Niña normalized by standard deviation utilizing the definitions from Table 1. Not surprisingly, both datasets produce higher $925 \mathrm{hPa}$ heights over the Amazon eastward to the Atlantic, with greater than 2SD positive $925 \mathrm{hPa}$ height differences from eastern Brazil into the Atlantic (Figure 6). Negative height differences in excess of $1.6 \mathrm{SD}$ are noted in the Equatorial Pacific in both datasets (Figure 6), with the area greater than 1.6 SD extending eastward from the equatorial Pacific to western South America in CFSR (Figure 6(a)). Across the Amazon Basin, an enhanced $925 \mathrm{hPa}$ height gradient difference is seen in CFSR relative to Re2 and is associated with greater $925 \mathrm{hPa}$ easterly flow in CFSR (cf. Figures 6(a) and 6(b)). Across the 


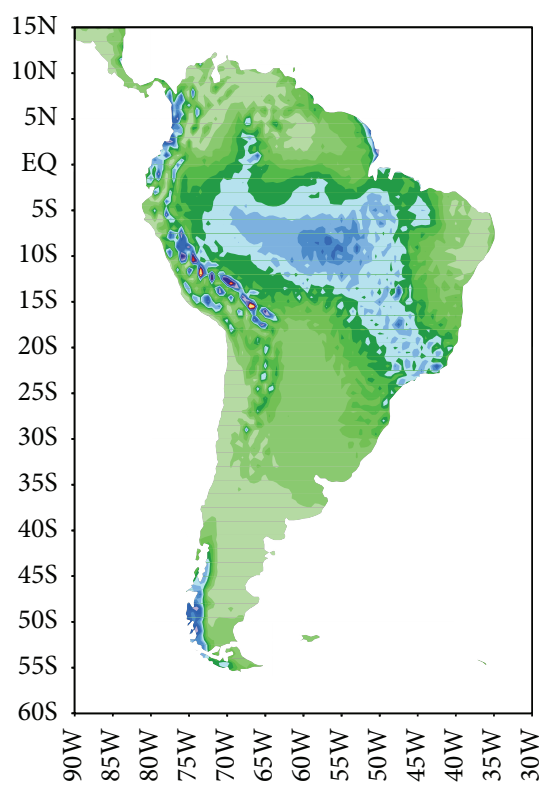

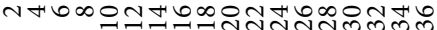

(a)

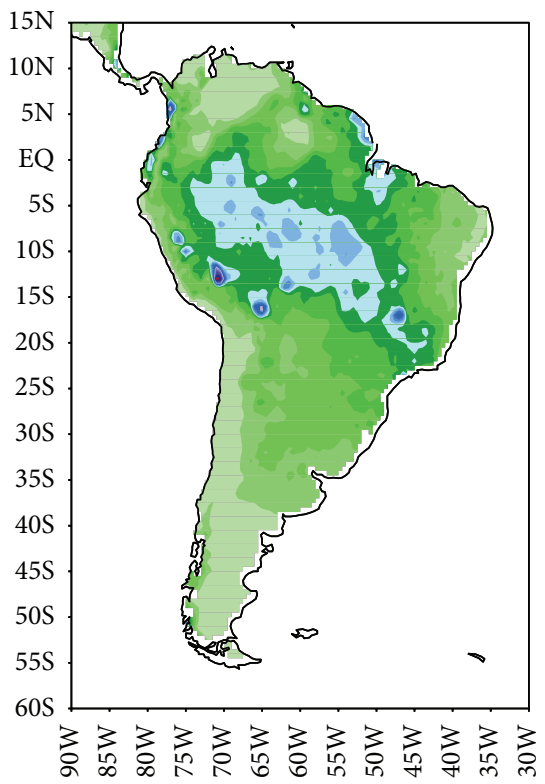

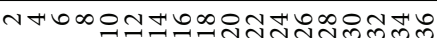

(c)

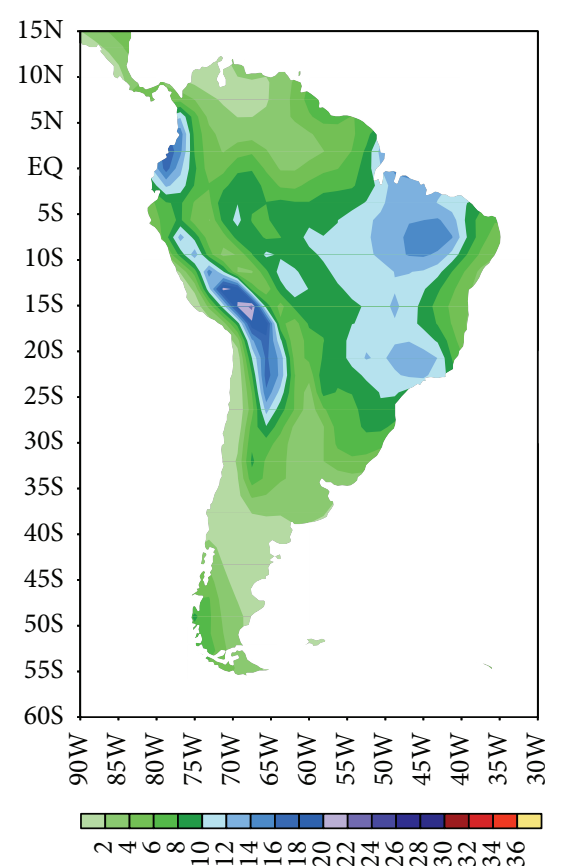

(b)

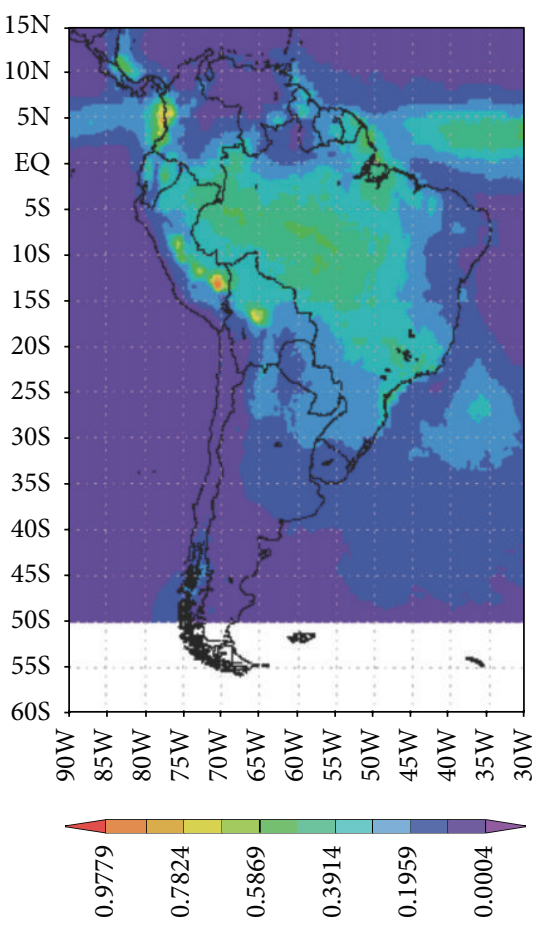

(d)

FIGURE 3: (a) CFSR DJF mean precipitation rate (mm/day) from 1979/1980 to 2008/2009, (b) like (a), except for Re2, (c) like (a) except for UD, and (d) DJF mean precipitation rate (mm/hr) from 1998/99 to 2011/2012 for TRMM data.

Andes, a narrow band of increased $925 \mathrm{hPa}$ height is seen across western Peru, likely reflecting the influence of the Cordillera Oriental (Figure 6(a)). This feature is absent in Re2, which shows a more circular area of increased $925 \mathrm{hPa}$ heights just east of Peru (Figure 6(b)).
It is interesting to assess potential model bias due to parameterization of low-level flow associated with the Andes as a function of El Niño. For example, Figure 7 shows anomalous $925 \mathrm{hPa}$ westerly flow occurring at the coast in both CFSR and Re2 for El Niño relative to La Niña. 


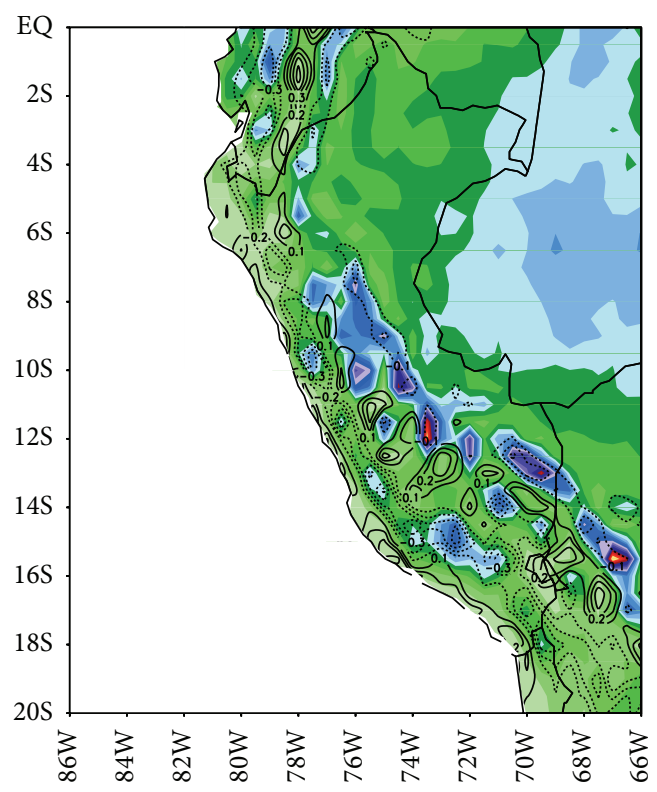

N

(a)

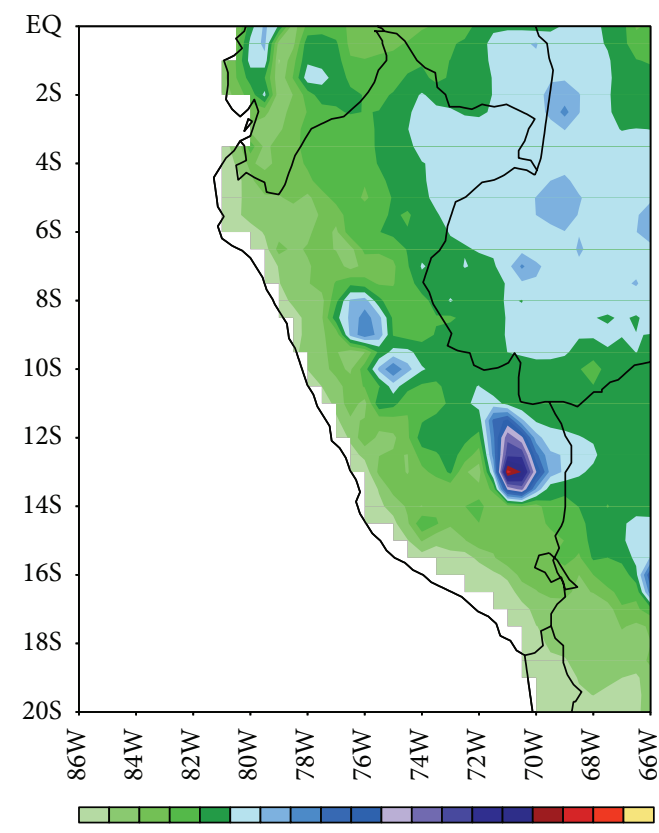

N

(c)

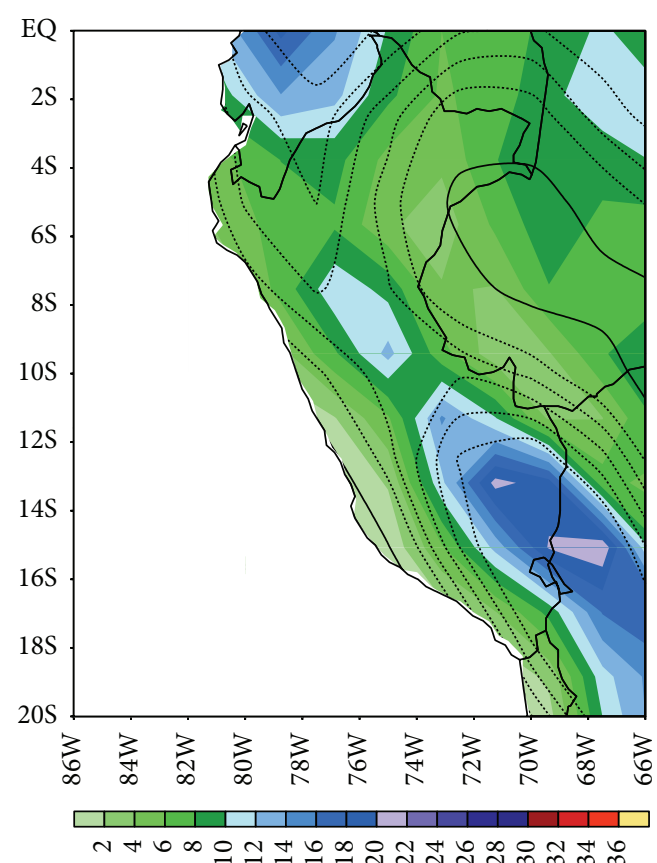

(b)

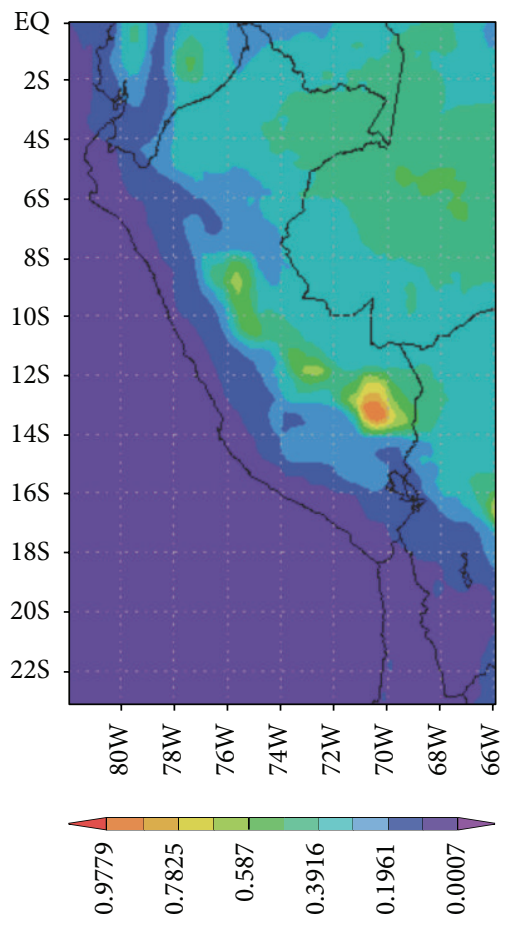

(d)

FIGURE 4: (a) CFSR DJF mean precipitation rate shaded (mm/day), $925 \mathrm{hPa}$ convergence contour $\left(\left(\mathrm{s}^{-1}\right) * 10000\right)$ from 1979/1980 to 2008/2009, (b) like (a), except for Re2 (convergence units: $\left(\mathrm{s}^{-1}\right) * 100000$ ), (c) like (a) except for UD precipitation only, and (d) DJF mean precipitation rate (mm/hr) from 1998/99 to 2011/2012 for TRMM data.

However, for CFSR, two narrow bands of $925 \mathrm{hPa}$ divergence/convergence appear from the coast to the Andes and are oriented parallel to the Andes (Figure 7(a)). In contrast, Re2 shows a broad area of $925 \mathrm{hPa}$ anomalous convergence across eastern Peru, with anomalous $925 \mathrm{hPa}$ divergence east of northern Peru/Ecuador (Figure 7(b)). The $925 \mathrm{hPa}$ El Niño/La Niña wind differences are also markedly different, with stronger easterlies prevailing along the Peru coast in Re2 (Figure 7(b)). However, a more complicated picture emerges for CFSR (Figure 7(a)). Instead of stronger easterlies, a 


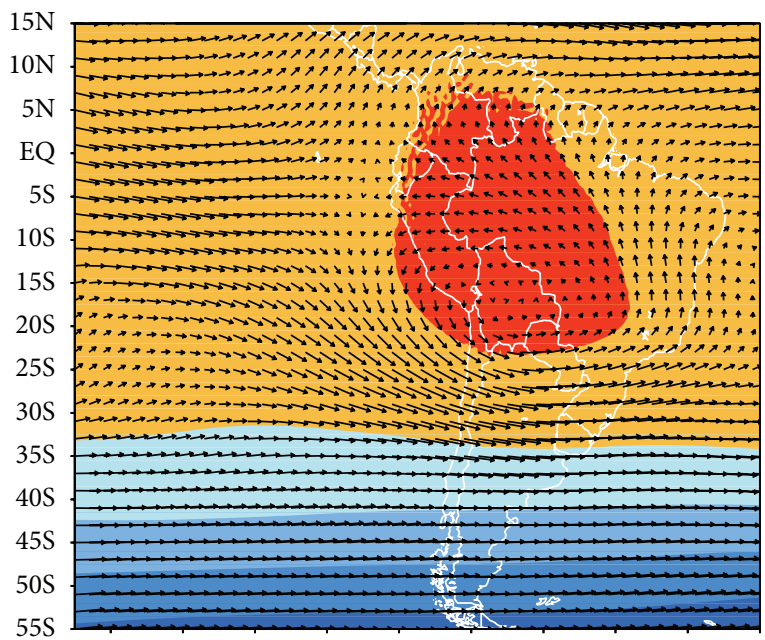

120W 110W 100W 90W 80W 70W 60W 50W 40W 30W

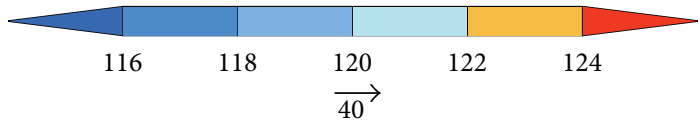

(a)

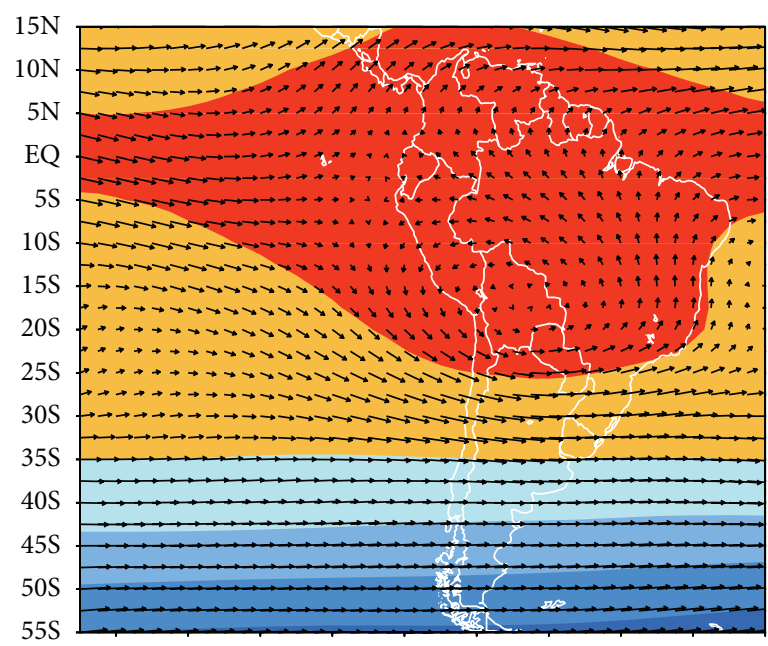

120W 110W 100W 90W 80W 70W 60W 50W 40W 30W

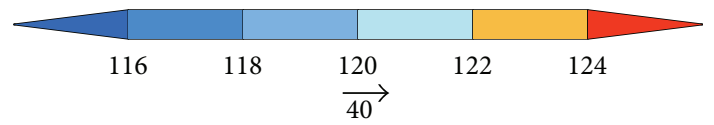

(b)

FIGURE 5: (a) CFSR DJF mean $200 \mathrm{hPa}$ height (meters/100), $200 \mathrm{hPa}$ wind vector (m/s) from 1979/1980 to 2008/2009 and (b) like (a), except for Re2.

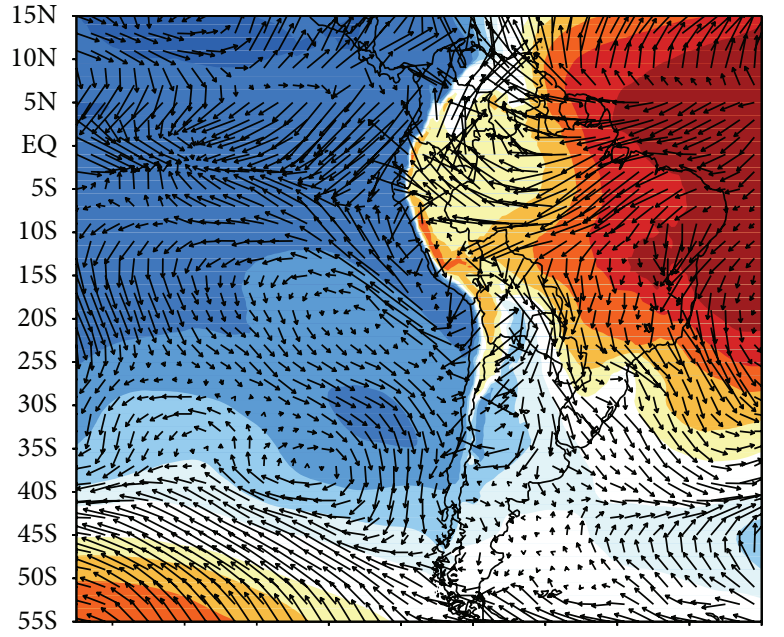

$120 \mathrm{~W} 110 \mathrm{~W} 100 \mathrm{~W} 90 \mathrm{~W} 80 \mathrm{~W} 70 \mathrm{~W}$ 60W $50 \mathrm{~W} 40 \mathrm{~W} 30 \mathrm{~W}$

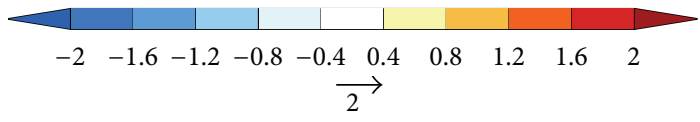

(a)
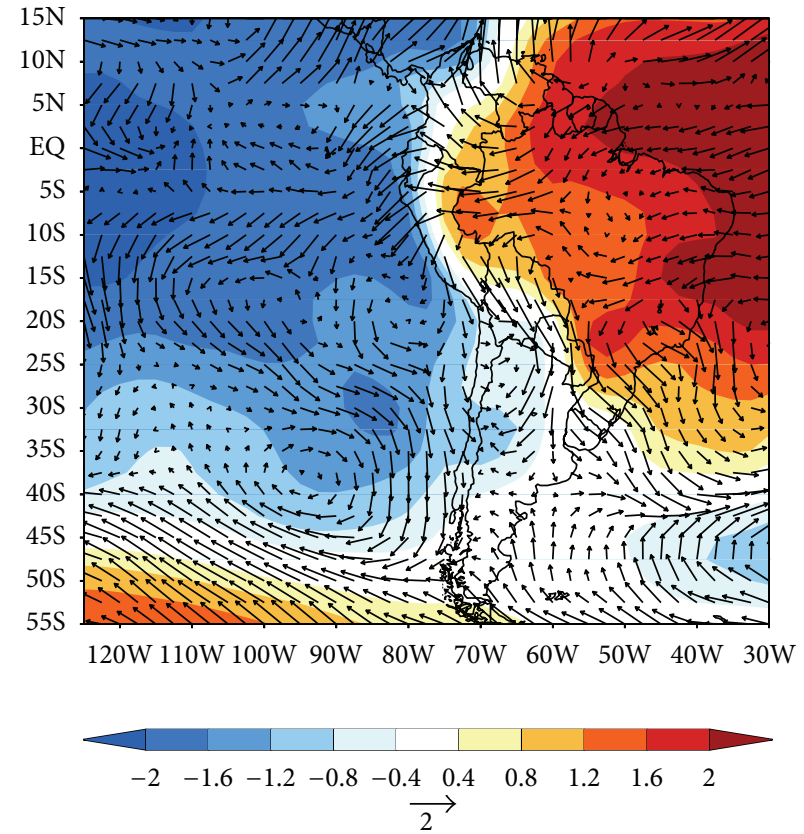

(b)

FIGURE 6: (a) CFSR DJF composite $925 \mathrm{hPa}$ height normalized by DJF mean standard deviation shaded (units: SD) and $925 \mathrm{hPa}$ wind normalized by DJF mean standard deviation vector (units: SD). Composites done for strong El Niño-strong La Niña, (b) like (a), except for Re2. 


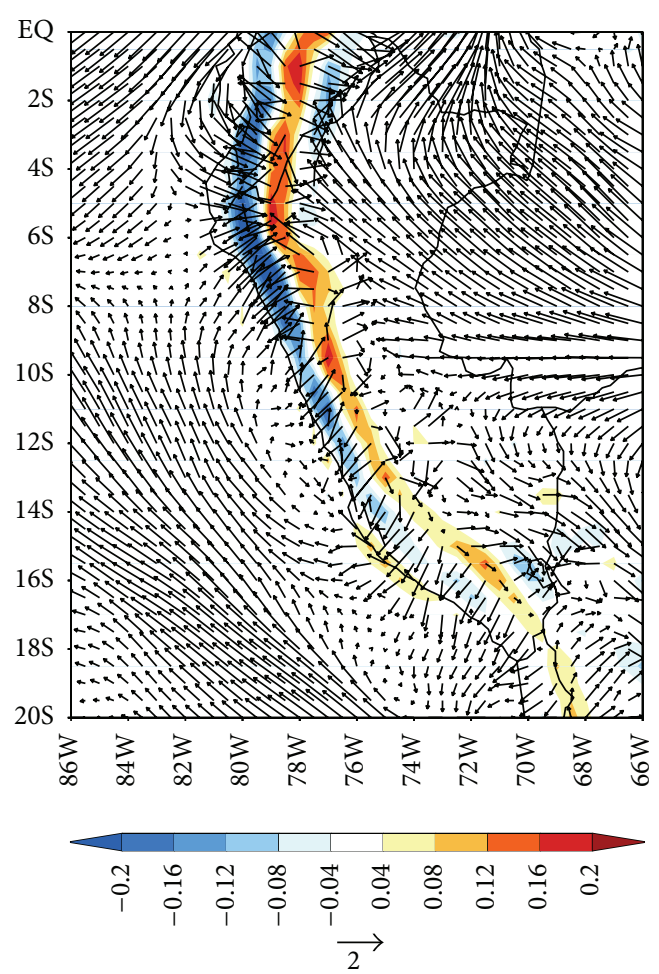

(a)
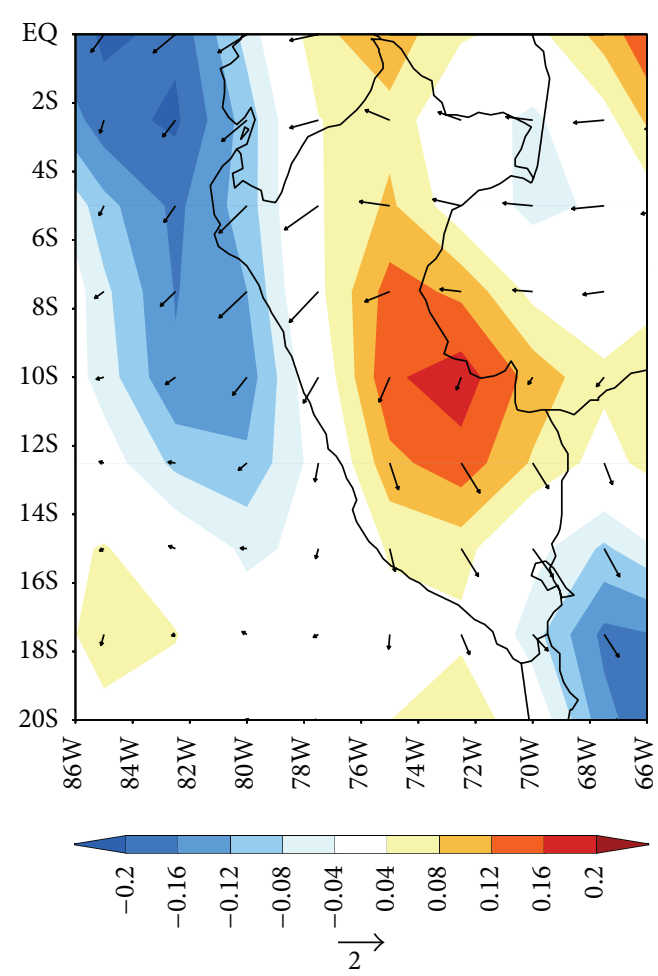

(b)

FIGURE 7: (a) CFSR DJF composite $925 \mathrm{hPa}$ convergence shaded (units: $\mathrm{s}^{-1} * 100000$ ) and $925 \mathrm{hPa}$ wind normalized by DJF mean standard deviation vector (units: SD). Composites done for strong El Niño-strong La Niña, (b) like (a), except for Re2 (units for 925 hPa convergence: $\left.\left(\mathrm{s}^{-1}\right) * 100000\right)$.

clockwise turning towards the Peruvian coast occurs towards the local maximum of $925 \mathrm{hPa}$ anomalous convergence in western Peru. This area of convergence appears to be driven by anomalous easterly downsloping off of the Cordillera Oriental converging with winds upsloping from the coast towards the Cordillera Oriental. Given that these results may be due to differences in model resolution rather than dynamical processes, caution should be exercised in assessing ENSO impacts in regions of large topographical gradients. El Niño-La Niña precipitation composites also show different spatial patterns between the CFSR and Re2 data (Figure 8). While both CFSR and Re2 exhibit significantly enhanced rainfall from the coast of Ecuador westward into the equatorial Pacific, and drying in the Amazon, the CFSR data shows Amazon drying eastward to $50^{\circ} \mathrm{W}$, while the Re2 data only shows significant drying ( $>1.6 \mathrm{SD})$ to approximately $65^{\circ} \mathrm{W}$ (cf. Figure 8(a) with Figure 8(b)). The drying seen in both datasets is attributable to above normal heights from an anomalously strong $925 \mathrm{hPa}$ ridge extending from the tropical Atlantic westward into South America (refer to Figure 6). The less extensive drying in the Re2 data may be due to $925 \mathrm{hPa}$ northerly wind anomalies near the Caribbean coast rapidly diminishing inland (e.g., $10^{\circ} \mathrm{S}, 50^{\circ} \mathrm{W}$ in Figure 8(b)) resulting in low-level convergence. In contrast, the CFSR data shows significant (approximately $2 \mathrm{SD}$ ) northeasterlies well into the Amazon (cf. Figures 8(a) and 8(b)). In both Re2 and CFSR, an anomalous $925 \mathrm{hPa}$ anticyclonic circulation appears between $15^{\circ} \mathrm{S}$ and $20^{\circ} \mathrm{S}\left(20^{\circ} \mathrm{S}\right.$ and $\left.25^{\circ} \mathrm{S}\right)$ west of South America in Re2 (CFSR). An anomalous $925 \mathrm{hPa}$ cyclonic circulation is also located west of Chile between $35^{\circ} \mathrm{S}$ and $40^{\circ} \mathrm{S}$ in both datasets (Figure 8).

The impacts of model resolution on precipitation due to topography can be assessed by examining a composite of El Niño/La Niña precipitation and $925 \mathrm{hPa}$ convergence (Figure 9). For the CFSR, increased rainfall in northwestern Peru is associated with a narrow zone of low-level $925 \mathrm{hPa}$ anomalous convergence (Figure 9(a)). For the Re2 data, a much broader $925 \mathrm{hPa}$ anomalous divergence/convergence pattern occurs, with the $925 \mathrm{hPa}$ anomalous convergence remaining offshore resulting in little impact of ENSO on rainfall (Figure 9(b)). Since comparing the reanalysis precipitation climatologies with observed precipitation showed inconsistency due to the models' representation of topography, the results shown above are likely due to the interaction of ENSO-induced circulation differences with model topography instead of a response directly due to ENSO.

As was the case for $200 \mathrm{hPa}$ climatology, $200 \mathrm{hPa}$ El Niño/La Niña composites are fairly consistent between the CFSR and Re2 data (Figure 10). Above normal heights cover the tropical Pacific, with below normal heights in the midlatitudes from the Pacific into the Atlantic, which is typical of an El Niño response. An anomalous anticyclonic circulation is also noted along the South American east coast between $30^{\circ} \mathrm{S}$ and $35^{\circ} \mathrm{S}$, while an anomalous cyclonic circulation 


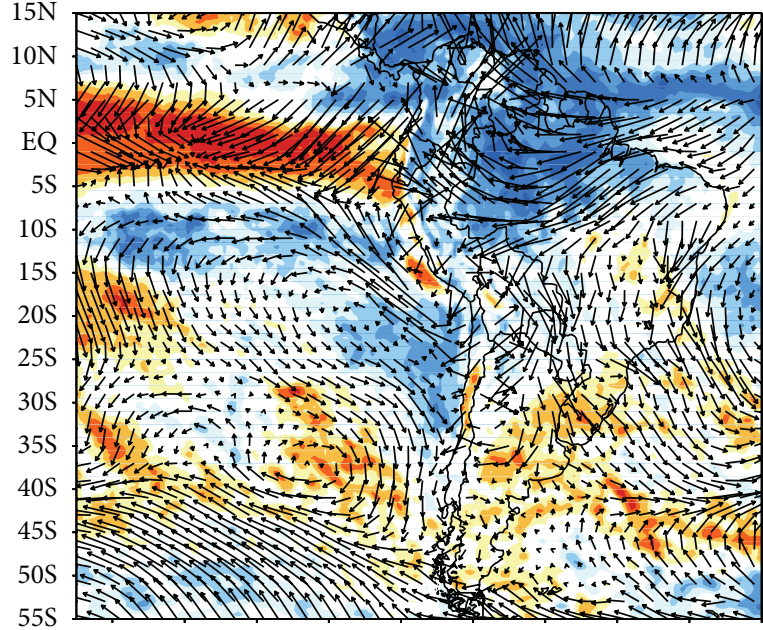

120W 110W 100W 90W 80W 70W 60W 50W 40W 30W

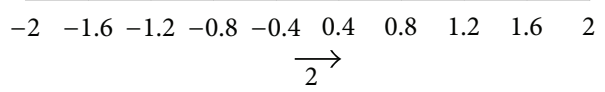

(a)

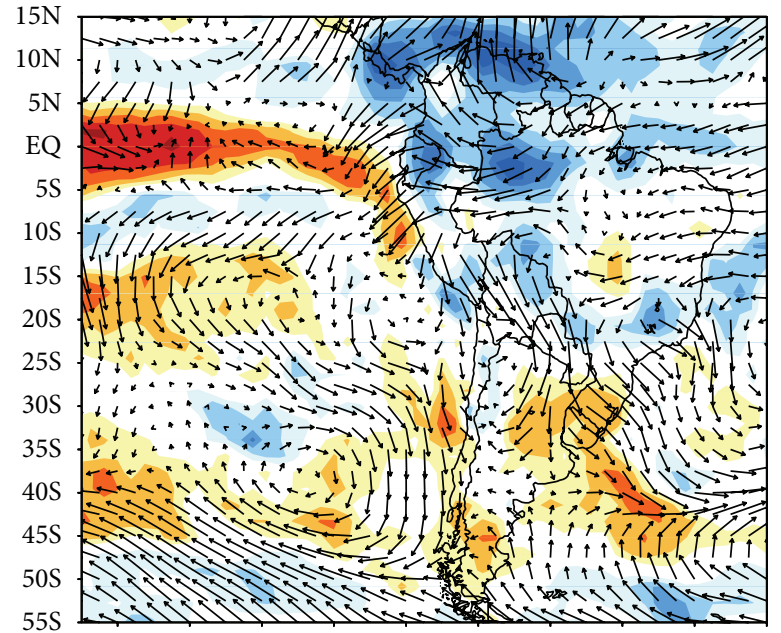

120W 110W 100W 90W 80W 70W 60W 50W 40W 30W

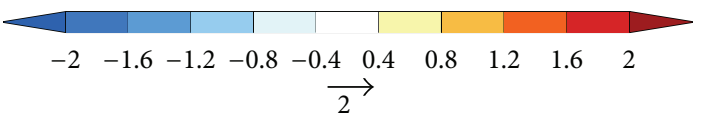

(b)

FIGURE 8: (a) CFSR DJF composite precipitation normalized by DJF mean standard deviation shaded (units: SD) and $925 \mathrm{hPa}$ wind normalized by DJF mean standard deviation vector (units: SD). Composites done for strong El Niño-strong La Niña, (b) like (a), except for Re2.

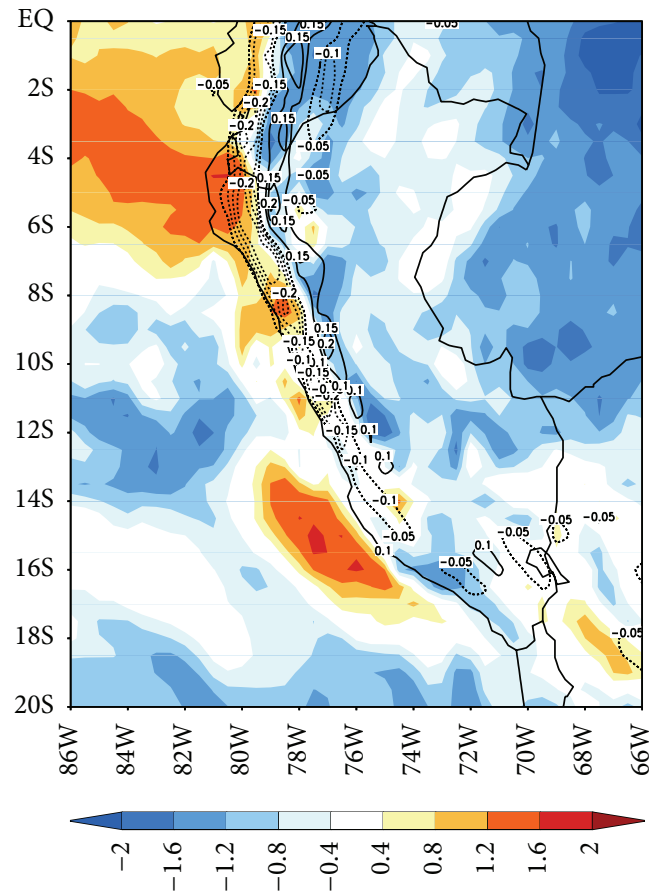

(a)

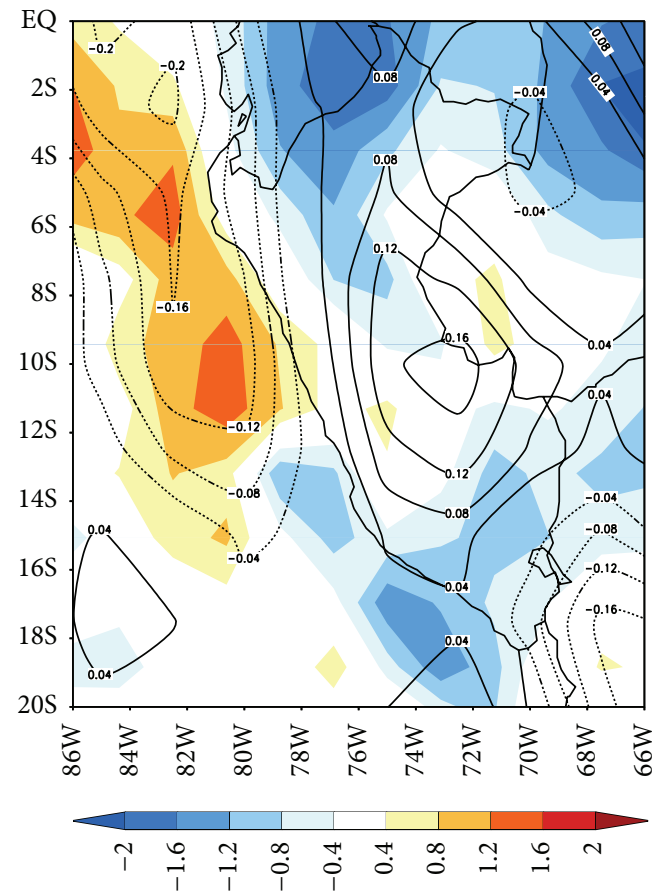

(b)

FIGURE 9: (a) CFSR DJF composite precipitation normalized by DJF mean standard deviation shaded (units: SD). Composite 925 hPa convergence contour (units: $\left(\mathrm{s}^{-1}\right) * 10000$ ). Composites done for strong El Niño-strong La Niña, (b) like (a), except for Re2 (units for 925 hPa convergence: $\left.\left(\mathrm{s}^{-1}\right) * 100000\right)$. 


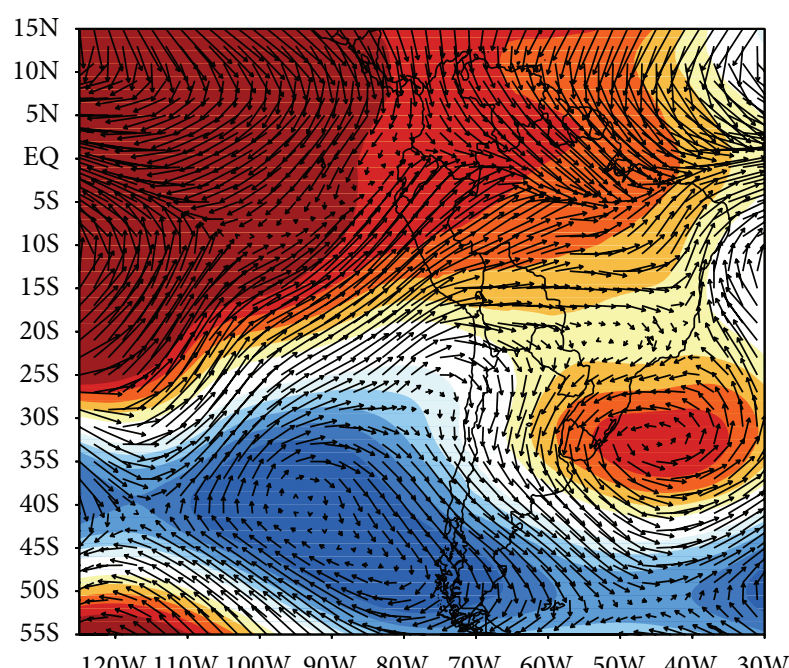

120W 110W 100W 90W 80W 70W 60W 50W 40W 30W

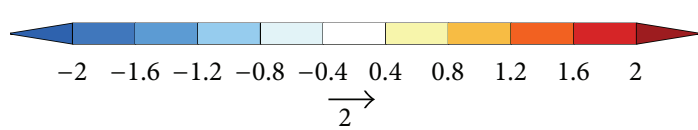

(a)
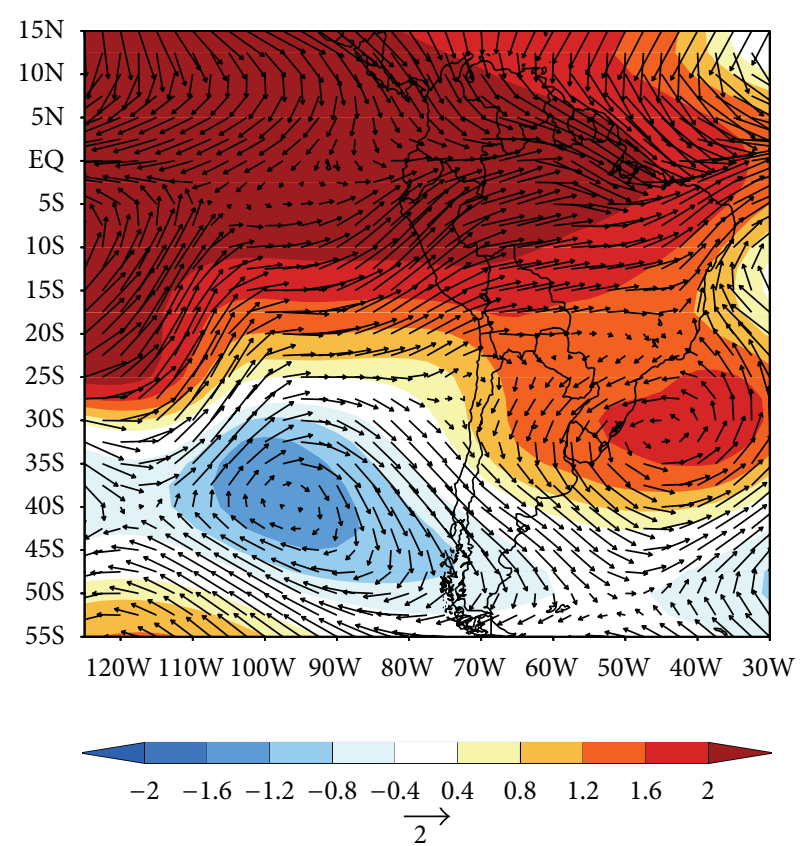

(b)

Figure 10: (a) CFSR DJF composite $200 \mathrm{hPa}$ height normalized by DJF mean standard deviation shaded (units: SD) and 200 hPa wind normalized by DJF mean standard deviation vector (units: SD). Composites done for strong El Niño-strong La Niña, (b) like (a), except for Re2.

appears west of Chile for both the CFSR and Re2 (Figure 9). While the spatial patterns are similar, difference in magnitude exists with the positive tropical Pacific $200 \mathrm{hPa}$ height anomalies being more significant ( $>2 \mathrm{SD}$ ) across northern South America in Re2 than in CFSR data $(<1.6 \mathrm{SD})$. The $200 \mathrm{hPa}$ cyclonic circulation west of Chile is also more significant $(>1.6 \mathrm{SD})$ in CFSR compared to $\operatorname{Re} 2(<1.2 \mathrm{SD})$ (Figure 10). In general, the magnitude of El Niño/La Niña $200 \mathrm{hPa}$ composites agrees fairly well between the CFSR and Re2 data. Since $200 \mathrm{hPa}$ is well above the level of the Andes, differences between CFSR and Re2 are likely attributed to assimilation differences rather than spatial resolution differences.

While the composites described above assess climate impacts due to the strongest El Niño/La Niña events, it is also useful to use correlation between ENSO utilizing the EIS index and climate variables to determine their overall relationship. The correlation between $925 \mathrm{hPa}$ height and ENSO is shown in Figure 11. Not surprisingly, large negative correlations extend from the South American coastline eastward to the Andes in both datasets consistent with El Niño conditions. The effects of topography are suggested by a narrow band of positive correlations downwind of the Andes from $5^{\circ} \mathrm{N}$ to $30^{\circ} \mathrm{S}$ in the CFSR data (Figure 11(a)), while the Re2 data only shows a broad area of positive correlation over western Brazil (Figure 11(b)), confirming our composite analysis showing that the Andes play a role in ENSO-induced circulation changes. Another difference between the CFSR and $\operatorname{Re} 2$ data is an area of negative correlations centered between $20^{\circ} \mathrm{S}$ and $25^{\circ} \mathrm{S}$ at $65^{\circ} \mathrm{W}$, which occurs in the CFSR data, but not in the Re2 data (cf. Figures 11(a) and 11(b)). The
CFSR analysis suggests a strengthened (weakened) Chaco low during El Niño (La Niña).

As shown by Marengo et al. [26], the South American Low-Level Jet (SALLJ) transports moisture from the Amazon via northeast trades. Once it encounters the Andes, it turns towards the southeast. An examination of the $925 \mathrm{hPa}$ zonal wind correlation shows an area of significant negative correlation across the Amazon in the CFSR data suggesting a stronger (weaker) SALLJ during El Niño (La Niña) (Figure 12(a)). In contrast, Re2 shows little response of the SALLJ to El Niño in this region; instead, an area of negative correlation extends from western Brazil to the coast of Peru and Ecuador (Figure 12(b)). Interestingly, an area of negative (positive) correlation south (north) of $18^{\circ} \mathrm{S}$ centered at $63^{\circ} \mathrm{W}$ also occurs in the CFSR data (Figure 12(a)). This suggests a reduction (enhancement) of upslope flow north of $18^{\circ} \mathrm{S}$ and an enhancement (reduction) of upslope flow south of $18^{\circ} \mathrm{S}$ associated with the SALLJ due to a stronger (weaker) Chaco low during El Niño (La Niña). This is apparent in the $925 \mathrm{hPa}$ wind El Niño/La Niña composite, where strong northeast trade winds across the Amazon abruptly change to anomalous northwesterlies at approximately $15^{\circ} \mathrm{S}, 63^{\circ} \mathrm{W}$, with a cyclonic turning back to anomalous northeasterlies at approximately $25^{\circ} \mathrm{S}, 63^{\circ} \mathrm{W}$ around a stronger Chaco low during El Niño (refer to Figure 6(a)). Overall, the Andes are reflected by several regions of positive correlation across western South America in CFSR, which do not occur in re2, once again suggesting ENSO-related wind changes interacting with topography in the CFSR data (cf. Figure 12(a) with Figure 12(b)). 

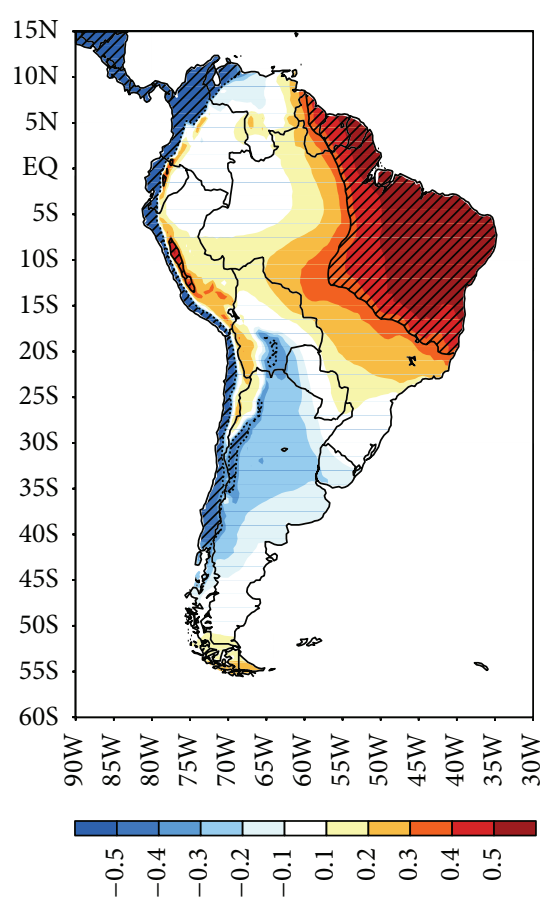

(a)

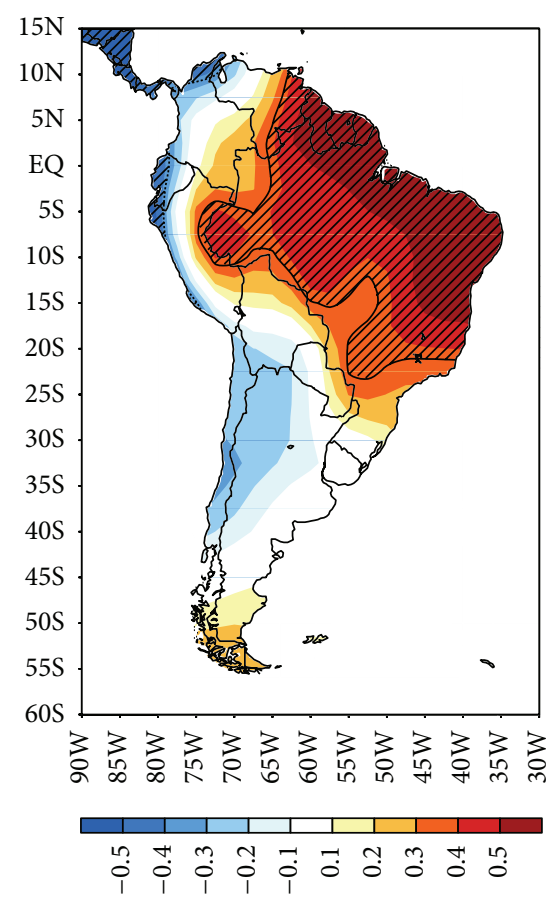

(b)

FIGURE 11: (a) CFSR correlation (DJF) between EIS index and $925 \mathrm{hPa}$ height. Hatching: 95\% significance for a 2-tailed test, (b) like (a), except for Re2.

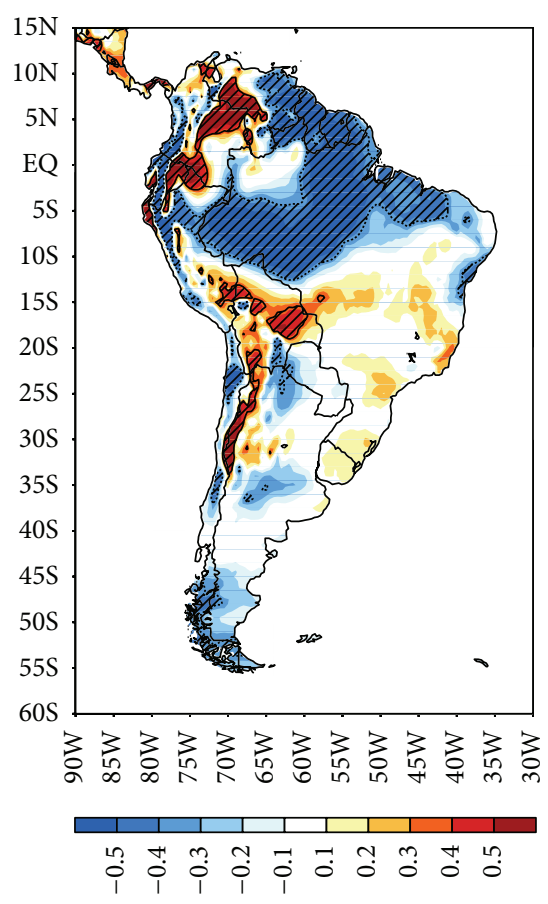

(a)

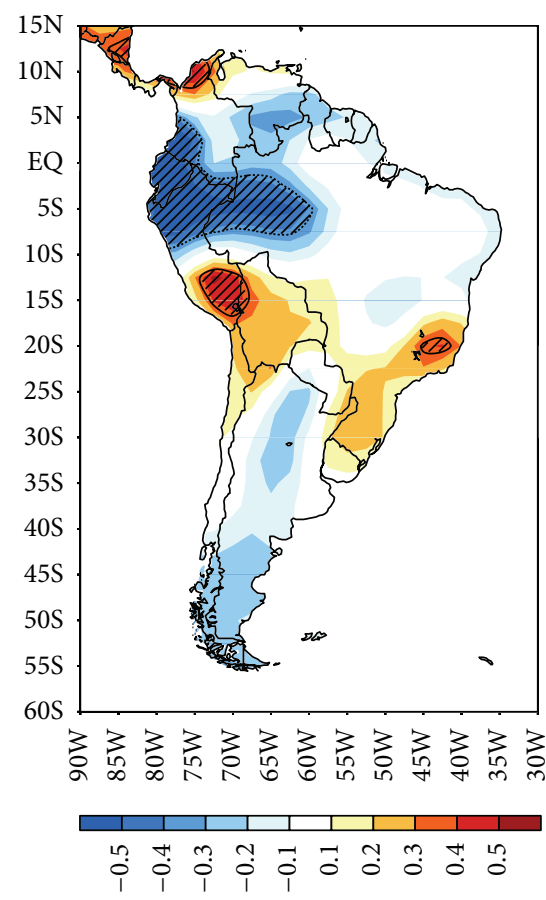

(b)

FIGURE 12: (a) CFSR correlation (DJF) between EIS index and $925 \mathrm{hPa}$ zonal wind. Hatching: 95\% significance for a 2-tailed test and (b) like (a), except for Re2. 


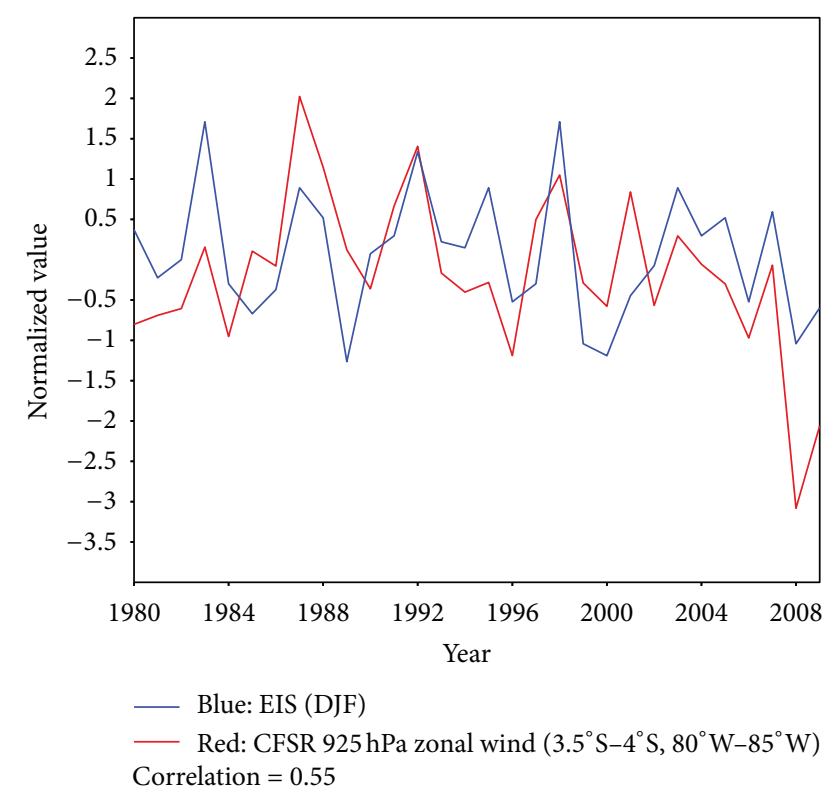

FIgURE 13: Time series of DJF EIS index (blue) versus CFS $925 \mathrm{hPa}$ zonal wind for a grid box from $3.5^{\circ} \mathrm{S}-4^{\circ} \mathrm{S}$ to $80^{\circ} \mathrm{W}-85^{\circ} \mathrm{W}$ (red).

Another interesting feature in the $925 \mathrm{hPa}$ wind correlation is an area of significant positive correlation in the coastal areas of Peru and Ecuador in CFSR, but not in Re2 (cf. Figures 12 (a) and 12(b)). This suggests that stronger (weaker) onshore winds occur during El Niño (La Niña) in this region. It also suggests that the CFSR dataset is able to detect this feature due to its higher spatial resolution. An examination of a time series of the EIS index versus the CFSR $925 \mathrm{hPa}$ zonal wind for a grid box in coastal Peru located from $3.5^{\circ} \mathrm{S}-4^{\circ} \mathrm{S}$ to $80^{\circ} \mathrm{W}-85^{\circ} \mathrm{W}$ normalized by standard deviation illustrates this robust relationship, with a significant correlation of 0.55 (Figure 13). To assess if this feature is only an artifact of the reanalysis data, we correlated precipitation with ENSO for CFSR, Re2, and UD (Figure 14). In both CFSR and UD, an area of positive correlation occurs in this area implying that stronger (weaker) onshore flow results in increased (decreased) precipitation during El Niño (La Niña) (Figures 14(a) and 14(c)), which is absent in Re2 (Figure 14(b)). These results are consistent with those of Wells [14], who used radiocarbon dating to confirm that floods associated with $\mathrm{El}$ Niño occurred throughout the Holocene in northern Peru, consistent with heavy rainfall seen in northern Peru in the modern record. Although the CFSR data is able to show details not seen in Re2, some caution is also warranted. For example, the CFSR shows decreased (increased) precipitation during El Niño (La Niña) in the Amazon as far east as $50^{\circ} \mathrm{W}$ along $10^{\circ} \mathrm{S}$, which is not evident in Re2 or UD (cf. Figure 14(a) with Figures 14(b) and 14(c)).

Finally, the $200 \mathrm{hPa}$ height correlations show that $200 \mathrm{hPa}$ heights rise (fall) north of $20^{\circ} \mathrm{S}$ and fall (rise) south of $35^{\circ} \mathrm{S}$ during El Niño (La Niña) typical of the upper-level tropospheric response to ENSO (Figure 15). However, the area of positive correlation in Re2 is larger in magnitude and spatial coverage in Re2 as it extends to as far south as $37^{\circ} \mathrm{S}$ in Re2 (Figure 15(b)). The area of negative correlation is also larger in magnitude and spatial coverage in CFSR as it extends as far north as $25^{\circ} \mathrm{S}$ along the Chilean coast (Figure 15(a)). These differences suggest that assimilation or resolution differences between Re2 and CFSR are possible causes.

\section{Conclusions}

The large-scale climatology of South American climate is well-represented in both the Re 2 and CFSR datasets. Greater detail of the precipitation and $925 \mathrm{hPa}$ wind is given by the CFSR, although caution is advised as shown by the UD precipitation supporting some features (e.g., rainfall north of Lake Titicaca) but not others (e.g., extensive areas of enhanced rainfall in other parts of the Andes). The greater detail of the rainfall over the Andes in the CFSR data is likely the impact of model topography on precipitation/low-level circulation instead of dynamical processes. This conclusion is supported by the lack of a banded rainfall structure in UD and TRMM data. The intensity of the rainfall in CFSR and Re2 over the Andes is also questionable given the tendency for both of these datasets to have high precipitation bias in these areas [25].

However, differences in $925 \mathrm{hPa}$ convergence may play a role in many of the precipitation differences that we see between the CFSR and Re2 in other regions, as suggested by an eastward displacement of the $925 \mathrm{hPa}$ wind convergence across the Amazon in Re2 relative to CFSR. In this instance, the CFSR outperforms the Re2 as UD's Amazon precipitation is in better agreement with CFSR.

The finer spatial resolution of the CFSR data also resulted in an increase in $925 \mathrm{hPa}$ heights across the Cordillera Oriental, with lower $925 \mathrm{hPa}$ heights and a cyclonic turning of the $925 \mathrm{hPa}$ winds on the lee-side associated with the Chaco low. In contrast, the Re 2 data showed no indication of decreased $925 \mathrm{hPa}$ heights linked to the Chaco low, although a cyclonic turning of the $925 \mathrm{hPa}$ wind was noted over Bolivia and northern Argentina.

At $200 \mathrm{hPa}$, the CFSR and Re2 climatologies are quite similar to each other with the Bolivian High well-represented. The high is a little stronger and more extensive in Re2. Since this is well above the topographical influence of the Andes, assimilation differences may play a role.

When evaluating the effects of ENSO on South American climate variability, several differences were noticed. Although composite analysis showed that both reanalysis datasets produced increased $925 \mathrm{hPa}$ geopotential heights over northeastern South America and adjacent areas of the tropical Atlantic and decreased $925 \mathrm{hPa}$ heights over the Equatorial Pacific and the adjacent coast of South America for El Niño relative to La Niña, a stronger anomalous $925 \mathrm{hPa}$ geopotential height in the CFSR data resulted in stronger anomalous $925 \mathrm{hPa}$ easterlies across the Amazon.

The impact of ENSO-induced changes over the Andes resulted in a zone of higher $925 \mathrm{hPa}$ geopotential heights aligned with the Andes mountains for El Niño relative to La Niña. Between the Andes and the coast, ENSO interacted with the models' local topography to produce two 

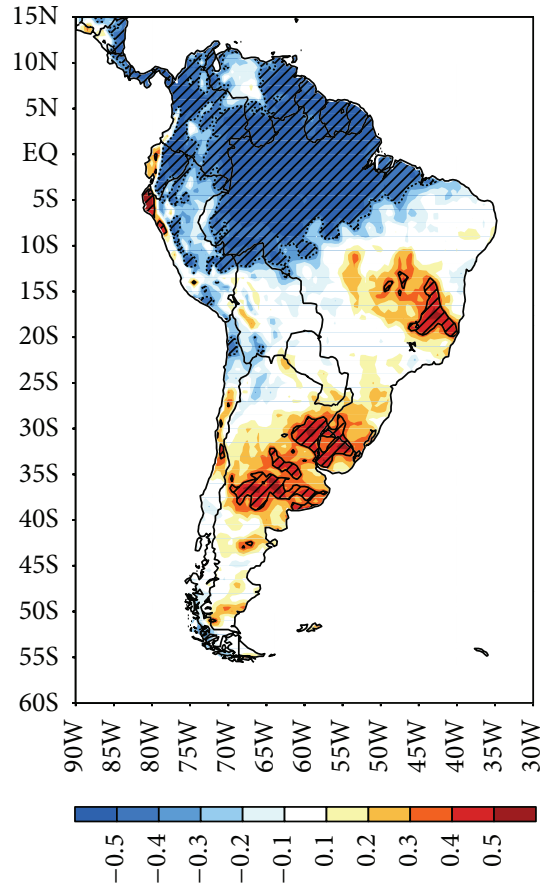

(a)

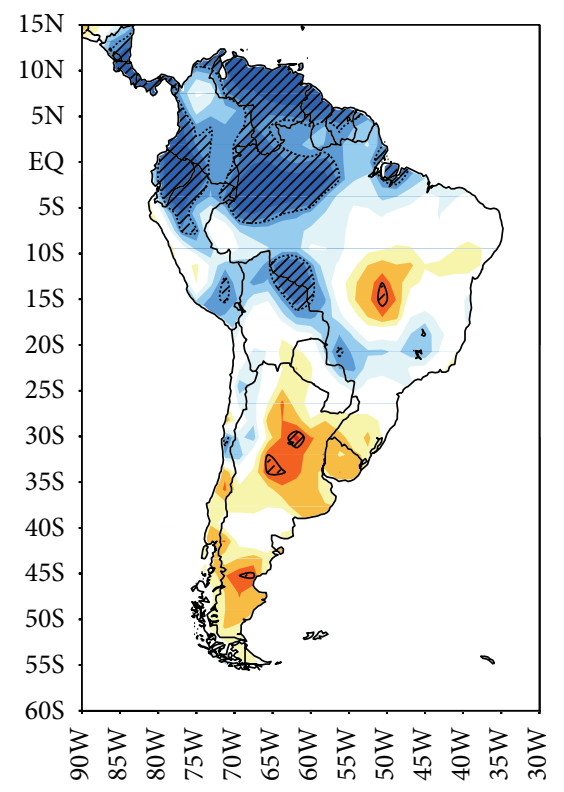

满

(b)

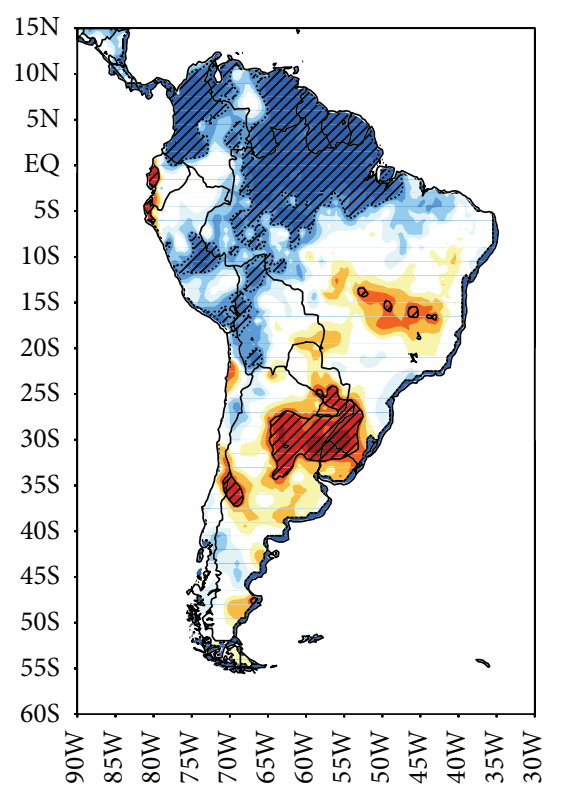

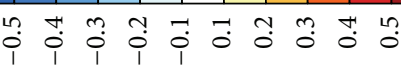

(c)

FIGURE 14: (a) CFSR correlation (DJF) between EIS index and precipitation. Hatching: 95\% significance for a 2-tailed test and (b) like (a), except for Re2, and (c) like (a) except for UD.

bands of $925 \mathrm{hPa}$ divergence/convergence for the CFSR data and a broad two-celled structure of $925 \mathrm{hPa}$ anomalous convergence for Re2. The CFSR precipitation composites reflected the impacts of local model topography, with heavier rain appearing in northwestern Peru for El Niño relative to La Niña. Although the CFSR precipitation composites fit well with the anomalous $925 \mathrm{hPa}$ convergence, the lack of confirmation from UD precipitation data suggests that the results are due to simulated topography instead of a dynamical response due to ENSO.

East of the Andes, composite analysis of the $925 \mathrm{hPa}$ height in the CFSR data suggests a stronger Chaco low, which 


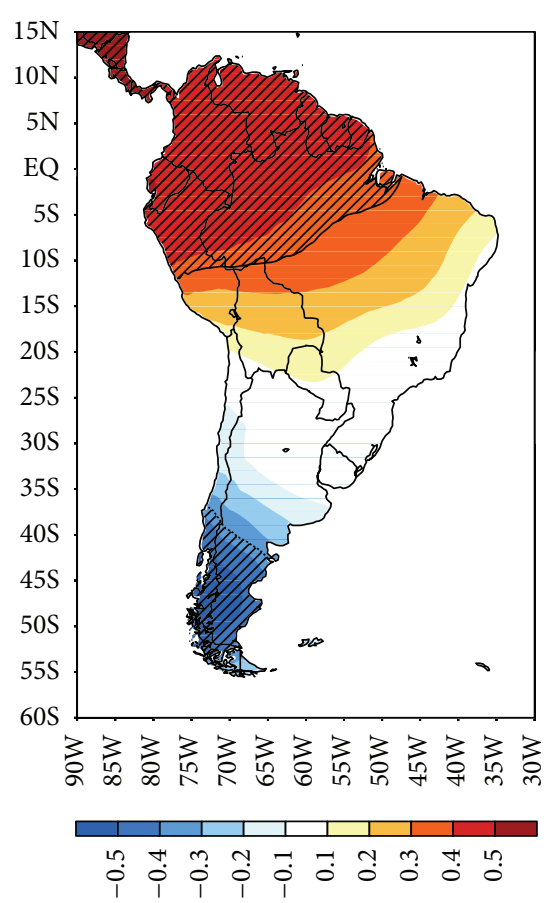

(a)

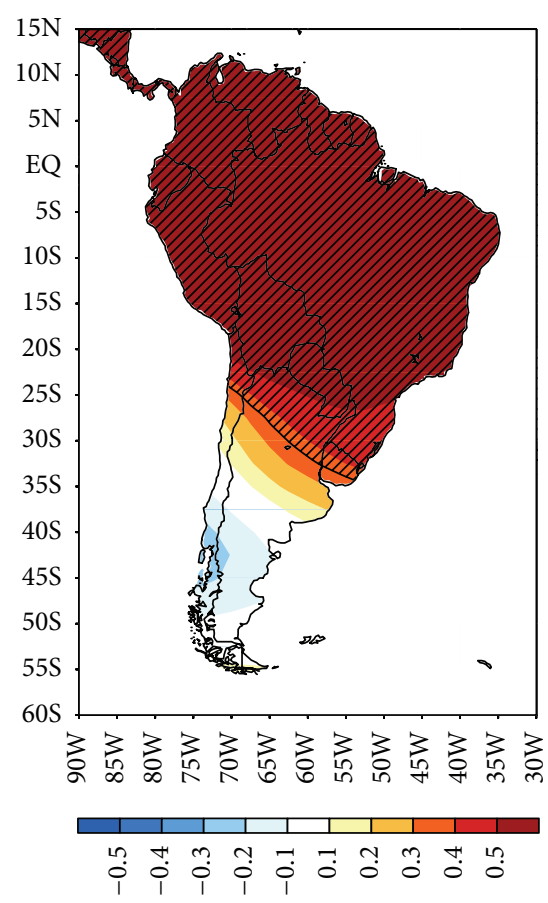

(b)

FIGURE 15: (a) CFSR correlation (DJF) between EIS index and $200 \mathrm{hPa}$ height. Hatching: 95\% significance for a 2-tailed test and (b) like (a), except for Re2.

is shown by a cyclonic turning of anomalous $925 \mathrm{hPa}$ northwesterly winds to anomalous northeasterlies at approximately $25^{\circ} \mathrm{S}, 63^{\circ} \mathrm{W}$ around the periphery of a stronger Chaco low during El Niño relative to La Niña.

The $200 \mathrm{hPa}$ height composites were in good agreement, with both datasets showing greater $200 \mathrm{hPa}$ heights at low latitudes and decreased $200 \mathrm{hPa}$ heights at high latitudes for El Niño relative to La Niña, which is not surprising since this is above the level of topographical influence. However, the positive values were greater in magnitude, and the negative values were lesser in magnitude in $\operatorname{Re} 2$. As was the case for the $200 \mathrm{hPa}$ climatology, assimilation differences likely played a major role.

While correlation analysis generally supported our composites, it did pick up some additional features. For example, the CFSR $925 \mathrm{hPa}$ zonal wind correlation showed a region of significant negative correlation across the Amazon suggesting a stronger (weaker) SALLJ during El Niño (La Niña), which was not evident in Re2. Although the response of the $925 \mathrm{hPa}$ wind over the Andes to ENSO can be attributed to model topography, an area of positive correlation along the coast of Ecuador/Peru in the CFSR data is likely due to the ability of the CFSR data to detect local low-level anomalous westerly (easterly) flow during El Niño (La Niña). This is supported by an increase (decrease) in precipitation due to El Niño (La Niña) as supported by the UD precipitation data.

Finally, the $200 \mathrm{hPa}$ height correlations were quite similar between Re2 and CFSR. However, the Re2 area of positive correlation in northern South America was larger in coverage and magnitude than that of CFSR. The area of negative correlation across southern South America was also greater in coverage and magnitude in CFSR relative to Re2. Both of these results are consistent with the composite analysis, with the differences between $\operatorname{Re} 2$ and CFSR being likely due to assimilation differences.

Our results generally agree with the ENSO-related South American impacts discussed in Garreaud et al. [1], Vuille et al. [12], and Coelho et al. [27]. The higher resolution of the CFSR data relative to Re2 is both beneficial and problematic; while the higher resolution of the CFSR data picks up more features than the Re 2 data, caution also needs to be exercised especially in areas of large topographical gradient. Future work will focus on mid-latitude South American climate, with an emphasis on storm tracks.

\section{Conflict of Interests}

Dr. Timothy Paul Eichler and Dr. Ana C. Londoño declare that there is no conflict of interests regarding the publication of this paper.

\section{References}

[1] R. D. Garreaud, M. Vuille, R. Compagnucci, and J. Marengo, "Present-day South American climate," Palaeogeography, Palaeoclimatology, Palaeoecology, vol. 281, no. 3-4, pp. 180-195, 2009.

[2] R. D. Garreaud, "The Andes climate and weather," Advances in Geosciences, vol. 22, pp. 3-11, 2009. 
[3] M. J. Rodwell and B. J. Hoskins, "Subtropical anticyclones and summer monsoons," Journal of Climate, vol. 14, no. 15, pp. 31923211, 2001.

[4] J. Houston and A. J. Hartley, "The central andean west-slope rainshadow and its potential contribution to the origin of hyper-aridity in the Atacama Desert," International Journal of Climatology, vol. 23, no. 12, pp. 1453-1464, 2003.

[5] M. Vuille, R. S. Bradley, M. Werner, R. Healy, and F. Keimig, "Modeling $\delta^{18} \mathrm{O}$ precipitation over the tropical Americas: 1. Interann- ual variability and climatic controls," Journal of Geophysical Research, vol. 108, no. D6, p. 4174, 2003.

[6] R. Garreaud, M. Vuille, and A. C. Clement, "The climate of the Altiplano: observed current conditions and mechanisms of past changes," Palaeogeography, Palaeoclimatology, Palaeoecology, vol. 194, no. 1-3, pp. 5-22, 2003.

[7] M. Falvey and R. D. Garreaud, "Moisture variability over the South American Altiplano during the South American low level jet experiment (SALLJEX) observing season," Journal of Geophysical Research D, vol. 110, no. D22, article 27, 2005.

[8] C. F. Ropelewski and M. S. Halpert, "Global and regional scale precipitation patterns associated with the El Niño/Southern Oscillation (ENSO)," Monthly Weather Review, vol. 115, pp. 1606-1626, 1987.

[9] P. Aceituno, "On the functioning of the Southern Oscillation in the South American sector. Part I: surface climate," Monthly Weather Review, vol. 116, no. 3, pp. 505-524, 1988.

[10] G. N. Kiladis and H. F. Diaz, "Global climatic anomalies associated with extremes in the Southern Oscillation," Journal of Climate, vol. 2, pp. 1069-1090, 1989.

[11] J. A. Marengo, "Interannual variability of surface climate in the Amazon Basin," International Journal of Climatology, vol. 12, no. 8, pp. 853-863, 1992.

[12] M. Vuille, R. S. Bradley, and F. Keimig, "Interannual climate variability in the Central Andes and its relation to tropical Pacific and Atlantic forcing," Journal of Geophysical Research D, vol. 105, no. 10, pp. 12447-12460, 2000.

[13] B. Rein, "How do the 1982/83 and 1997/98 El Niños rank in a geological record from Peru?" Quaternary International, vol. 161, no. 1, pp. 56-66, 2007.

[14] L. E. Wells, "Holocene history of the El Nino phenomenon as recorded in flood sediments of northern coastal Peru," Geology, vol. 18, no. 11, pp. 1134-1137, 1990.

[15] E. Kalnay, M. Kanamitsu, R. Kistler et al., "The NCEP/NCAR 40-year reanalysis project," Bulletin of the American Meteorological Society, vol. 77, no. 3, pp. 437-471, 1996.

[16] M. Kanamitsu, W. Ebisuzaki, J. Woollen et al., "NCEP-DOE AMIP-II reanalysis (R-2)," Bulletin of the American Meteorological Society, vol. 83, no. 11, pp. 1631-1643, 2002.

[17] S. Saha, S. Moorthi, and H. -L. Pan, “The NCEP climate forecast system reanalysis," Bulletin of the American Meteorological Society, vol. 91, pp. 1015-1057, 2010.

[18] D. R. Legates and C. J. Willmott, "Mean seasonal and spatial variability in gauge-corrected, global precipitation," International Journal of Climatology, vol. 10, no. 2, pp. 111-127, 1990.

[19] G. J. Huffman, R. F. Adler, P. Arkin et al., "The Global Precipitation Climatology Project (GPCP) combined precipitation dataset," Bulletin of the American Meteorological Society, vol. 78, no. 1, pp. 5-20, 1997.

[20] B. Rudolf, H. Hauschild, W. Rueth, and U. Schneider, "Terrestrial precipitation analysis: operational method and required density of point measurements," in Global Precipitations and
Climate Change, M. Desbois and F. Desalmond, Eds., vol. 26 of NATO ASI Series I, pp. 173-186, Springer, 1994.

[21] G. J. Huffman, "Estimates of root-mean-square random error for finite samples of estimated precipitation," Journal of Applied Meteorology, vol. 36, no. 9, pp. 1191-1201, 1997.

[22] G. J. Huffman, R. F. Adler, B. Rudolf, U. Schneider, and P. R. Keehn, "Global precipitation estimates based on a technique for combining satellite-based estimates, rain gauge analysis, and NWP model precipitation information," Journal of Climate, vol. 8, no. 5, pp. 1284-1295, 1995.

[23] V. E. Kousky and R. W. Higgins, "An alert classification system for monitoring and assessing the ENSO cycle," Weather and Forecasting, vol. 22, no. 2, pp. 353-371, 2007.

[24] C. Vera, W. Higgins, J. Amador et al., "Toward a unified view of the American monsoon systems," Journal of Climate, vol. 19, no. 20, pp. 4977-5000, 2006.

[25] V. B. S. Silva, V. E. Kousky, and R. W. Higgins, "Daily precipitation statistics for South America: an intercomparison between NCEP reanalyses and observations," Journal of Hydrometeorology, vol. 12, no. 1, pp. 101-117, 2011.

[26] J. A. Marengo, W. R. Soares, C. Saulo, and M. Nicolini, "Climatology of the low-level jet east of the andes as derived from the NCEP-NCAR reanalyses: characteristics and temporal variability," Journal of Climate, vol. 17, pp. 2261-2280, 2004.

[27] C. A. S. Coelho, C. B. Uvo, and T. Ambrizzi, "Exploring the impacts of the tropical Pacific SST on the precipitation patterns over South America during ENSO periods," Theoretical and Applied Climatology, vol. 71, no. 3-4, pp. 185-197, 2002. 

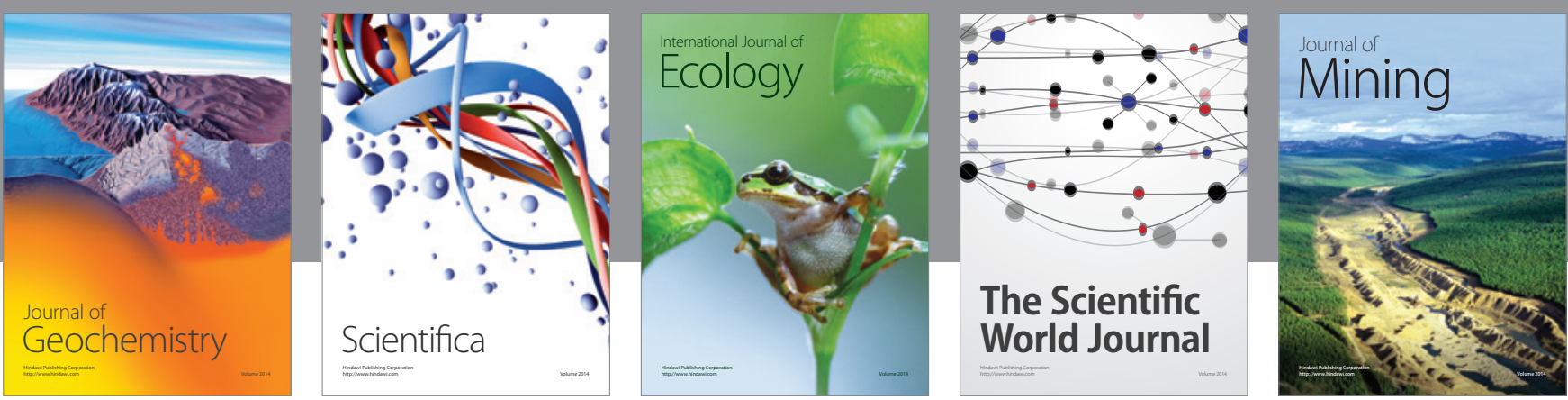

The Scientific World Journal
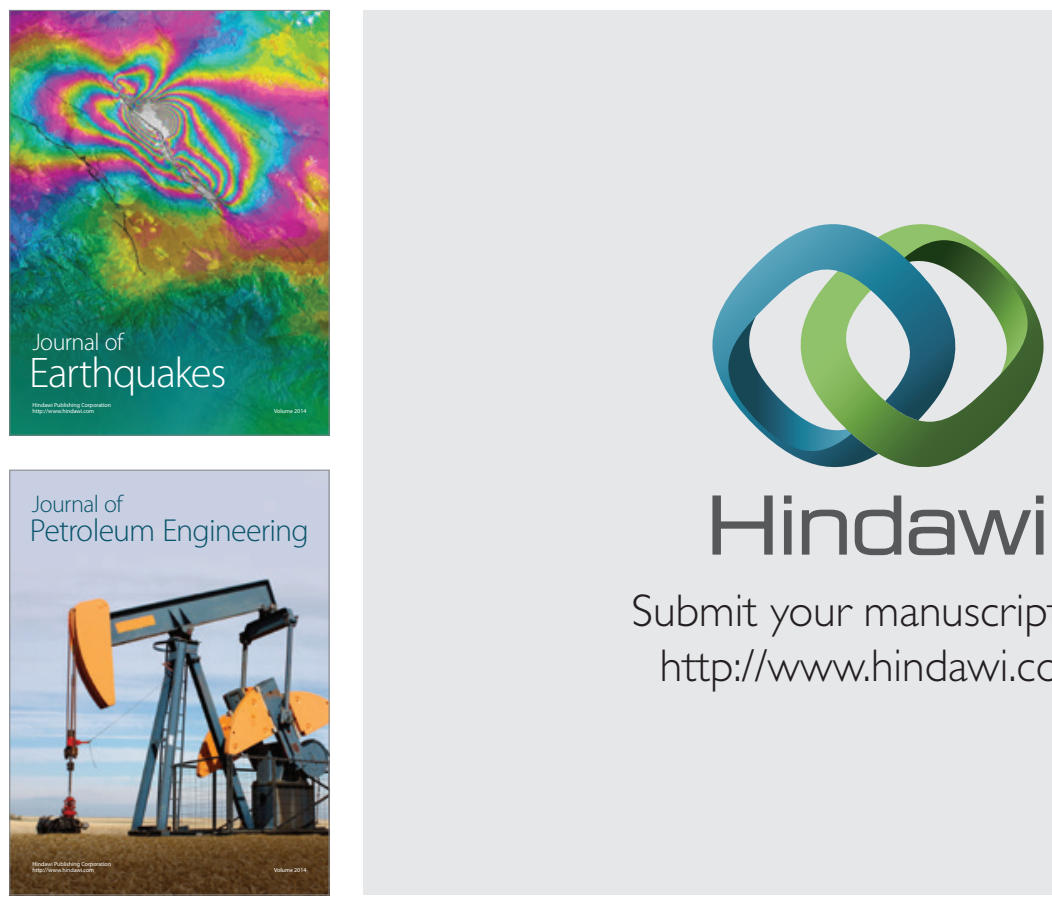

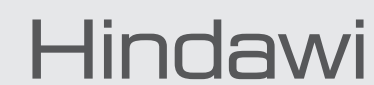

Submit your manuscripts at

http://www.hindawi.com
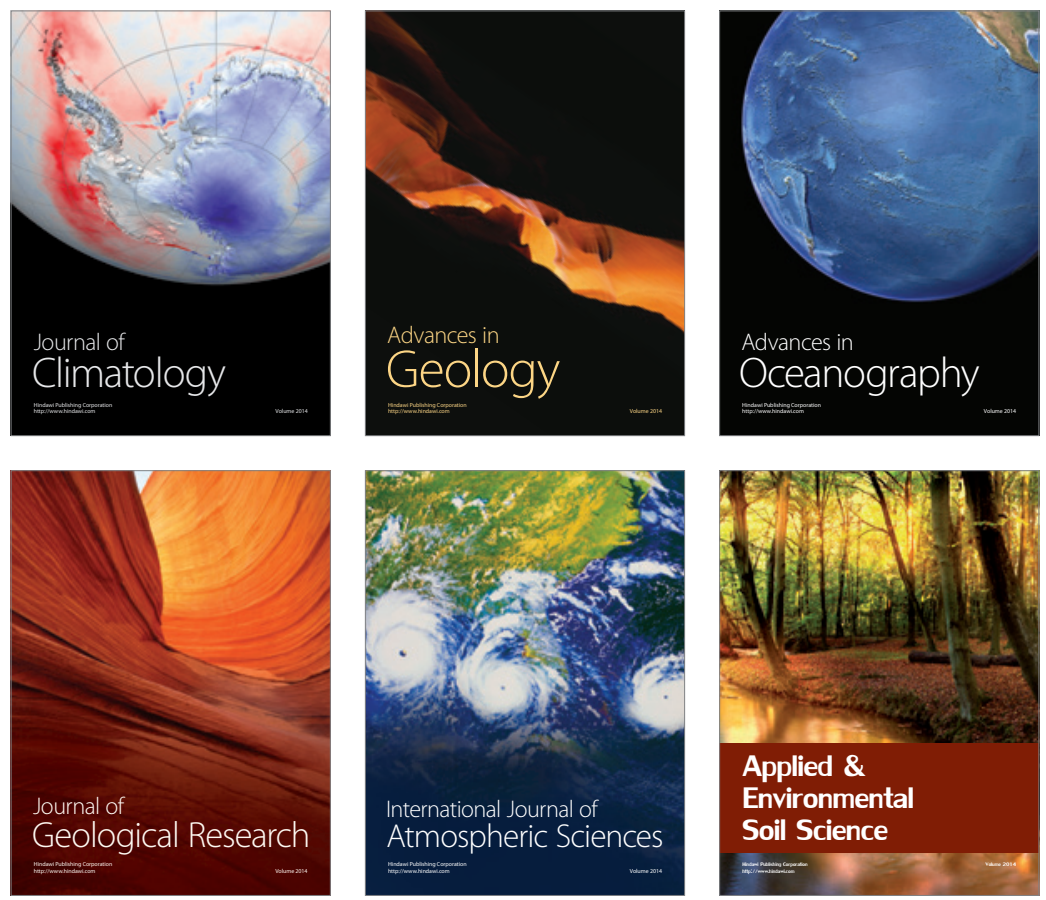
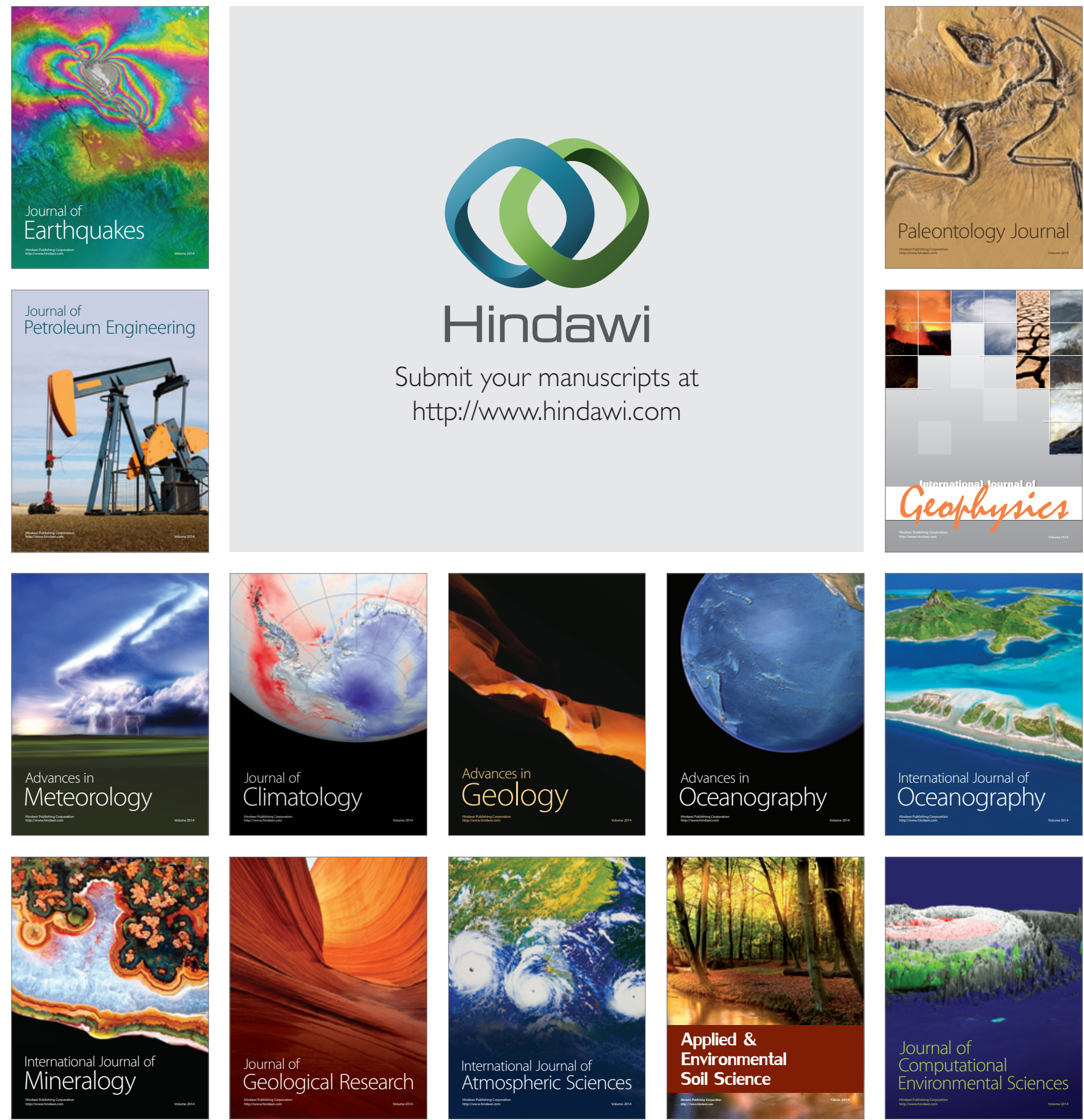